CHAPTER 50

\title{
The role of mesenchymal stromal cells in the treatment of ulcerative colitis and Crohn's disease
}

\author{
Céline Gregoire ${ }^{a}$, Chantal Lechanteur ${ }^{b}$, Alexandra Briquet ${ }^{b}$, Etienne Baudoux ${ }^{b}$, Olivier Giet ${ }^{b}$, Olivier Delloye ${ }^{b}$, Frédéric \\ Baron $^{a}$, Edouard Louis, and Yves Beguin ${ }^{\mathrm{a}, \mathrm{b}, *}$
}

${ }^{a}$ Department of Hematology, Le Centre Hospitalier Universitaire of Liège and Unit of Hematology, University of Liège, Liège, Belgium

${ }^{\mathrm{b}}$ Laboratory of Cell and Gene Therapy (LTCG), Le Centre Hospitalier Universitaire of Liège and University of Liège, Liège, Belgium

${ }^{\mathrm{c}}$ Department of Gastro-Enterology, Le Centre Hospitalier Universitaire of Liège and University of Liège, Liège, Belgium

\section{Chapter menu}

50.1 Inflammatory bowel diseases, 730

50.2 Pathogenesis of inflammatory bowel diseases, 731

50.3 Treatment of Crohn's disease, 734

50.3.1 Current treatment options for Crohn's disease, 734

50.3.2 Potential treatment options, 735

50.4 Treatment of ulcerative colitis, 737

50.4.1 Current treatment options for ulcerative colitis, 737

50.4.2 Potential new treatment options, 737

50.5 Properties of mesenchymal stromal cells, 737

50.5.1 Immunomodulation, 738

50.5.2 Immune tolerance, 739

50.5.3 Tissue regeneration, 740

50.5.4 Homing, 740

50.5.5 Differentiation and stimulation of tissue repair, 740

50.6 Mesenchymal stromal cell administration in inflammatory bowel diseases, 740

50.6.1 Mesenchymal stromal cell administration for fistulizing Crohn's disease, 741

50.6.2 Autologous mesenchymal stromal cell administration for fistulizing Crohn's disease, 741
50.6.3 Allogeneic mesenchymal stromal cell administration for fistulizing Crohn's disease, 742

50.6.4 Autologous mesenchymal stromal cell administration for luminal inflammatory bowel diseases, 742

50.6.5 Allogeneic mesenchymal stromal cell administration for luminal inflammatory bowel diseases, 742

50.7 The future of mesenchymal stromal cell treatment in inflammatory bowel diseases, 743

50.7.1 Ongoing protocols, 743

50.8 Issues to be resolved, 744

50.8.1 Source of mesenchymal stromal cells, 744

50.8.2 Autologous versus allogeneic mesenchymal stromal cells, 745

50.8.3 Dosage and modalities of administration, 745

50.8.4 Concomitant use of other drugs, 745

50.9 Safety, 745

50.10 Conclusions, 745

References, 746

\subsection{Inflammatory bowel diseases}

Inflammatory bowel diseases (IBDs) are chronic relapsing diseases associated with debilitating symptoms and leading to progressive intestinal tissue damage and disability (Figure 50.1).

Crohn's disease (CD) can affect any part of the gastrointestinal tract, and lesions are often segmental and transmural. The disease was named after gastroenterologist Dr Burrill Bernard

* Corresponding author: University of Liège, Department of Hematology, Le Centre Hospitalier Universitaire Sart Tilman, 4000 Liège, Belgium. Email: yves. beguin@chu.ulg.ac.be.
Crohn, who, in 1932, together with two other colleagues at Mount Sinai Hospital in New York, described a series of patients with inflammation of the terminal ileum of the small intestine, the area most commonly affected by the illness. Active CD is characterized by focal inflammation with granulomas and formation of fistula tracts or abscesses, and chronic lesions include fibrosis and stricture of the bowel (Figure 50.2).

In ulcerative colitis (UC), mucosal inflammation is continuous and limited to the mucosa and superficial submucosa. Lesions can affect the rectum and to a variable extent the colon, without granulomas or fistulas. The age of onset of IBD is most frequently in late adolescence or early adulthood, and the disease is equally

The Biology and Therapeutic Application of Mesenchymal Cells, First Edition. Edited by Kerry Atkinson.

(c) 2017 John Wiley \& Sons, Inc. Published 2017 by John Wiley \& Sons, Inc. 


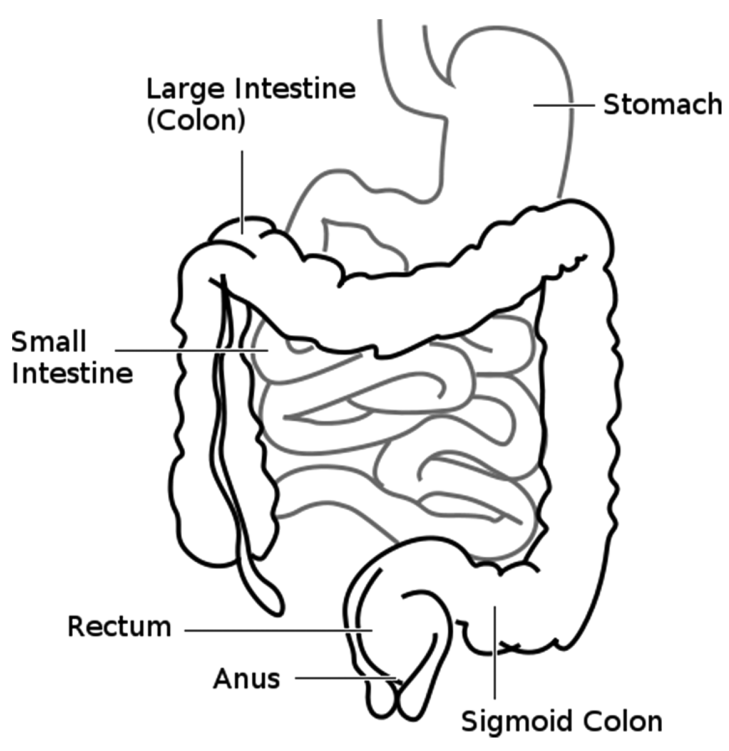

Figure 50.1 Diagram of the human intestine. Drawn by Duncan Lock and released into the Public Domain. Source: http://commons.wikimedia.org/ wiki/File:Intestine-diagram.svg\#mediaviewer/File:Intestine-diagram.svg.

distributed between the sexes. The incidence and prevalence are stable in high-incidence areas (northern Europe and North America), and rising in low-incidence areas (southern Europe, Asia, and most developing countries) [1,2].

Symptoms of CD are heterogeneous, but commonly include chronic diarrhea, abdominal pain, weight loss, anorexia, and/or fever. Rectal bleeding occurs commonly in UC, while perianal fissures, fistulas, or abscesses can occur in CD. Extraintestinal features can be related to extraintestinal inflammation, such as joint inflammation (spondyloarthritis, peripheral arthritis),

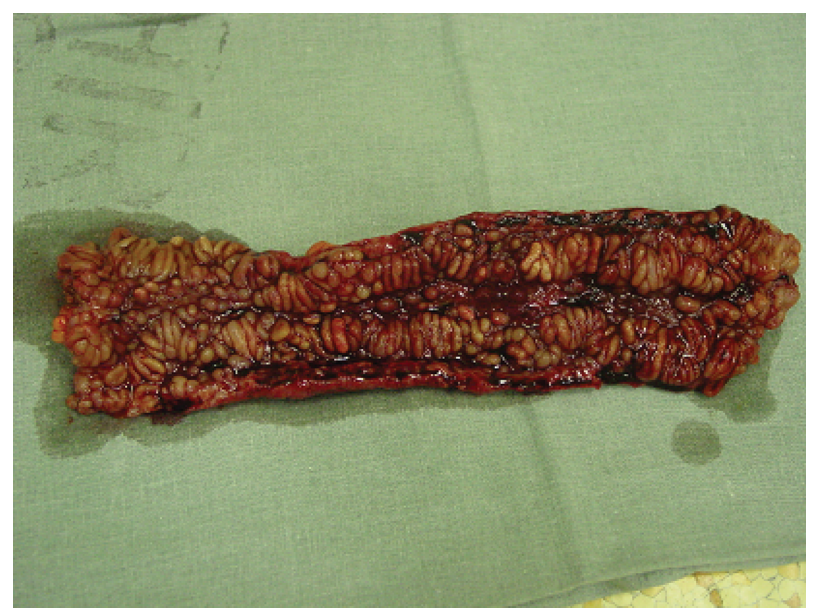

Figure 50.2 A portion of resected jejunum showing the typical cobblestone appearance of CD affecting the jejunum. Source: http://commons .wikimedia.org/wiki/File:Crohn_Jejunum.PNG\#mediaviewer/File: Crohn_Jejunum.PNG.

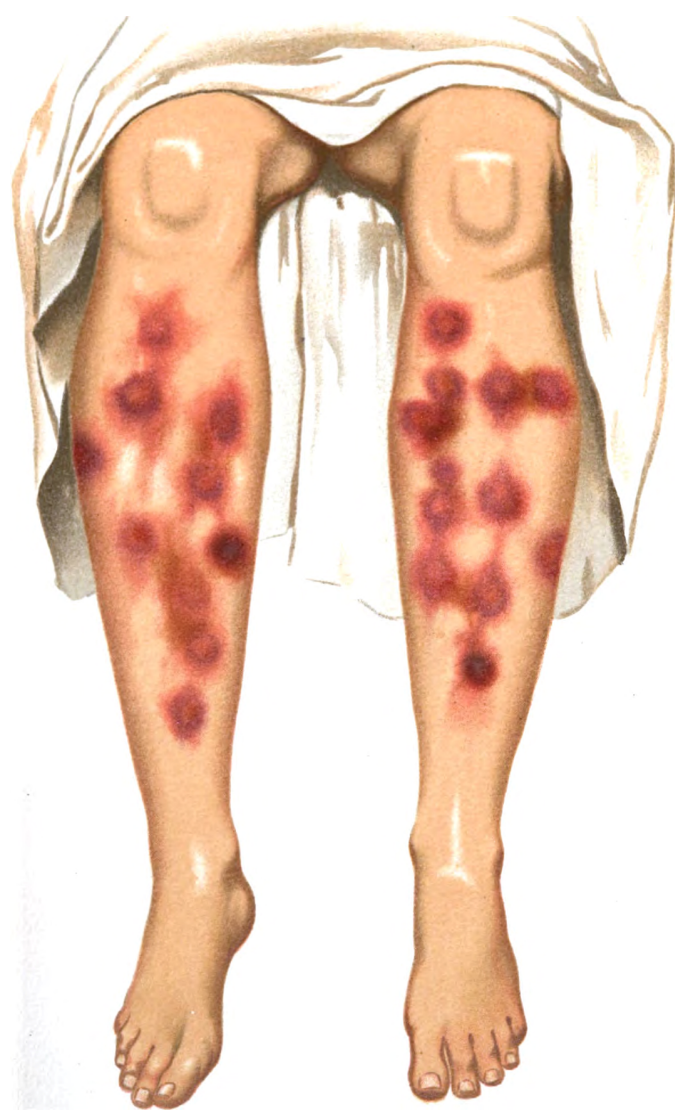

Figure 50.3 Erythema nodosum is an inflammatory condition characterized by inflammation of the fat cells under the skin, resulting in tender red nodules or lumps. It can be caused by a variety of conditions and typically resolves spontaneously within 3-6 weeks. The commonest distribution of erythema nodosum is on the shins - the anterior aspect of the lower legs. Source: 1905, William Wood and Company.

cutaneous manifestations - erythema nodosum (Figure 50.3), pyoderma gangrenosum (Figure 50.4) - ocular inflammation (uveitis, episcleritis, sclero-conjunctivitis), and primary sclerosing cholangitis, or are consequences of malabsorption (cholelithiasis, nephrolithiasis, and osteoporosis) [3].

The diagnosis is based on clinical evaluation and a combination of endoscopic, histological, radiological (computed tomography scan, magnetic resonance imaging (MRI)), and/or biochemical (C-reactive protein (CRP), full blood count, and fecal calprotectin) investigations. The histologic diagnosis is based on the presence of discontinuous chronic inflammation, focal crypt irregularity, and granulomas in CD [4].

\subsection{Pathogenesis of inflammatory bowel diseases}

The etiology of IBD is multifactorial, polygenic [5], and environmental [6] and includes an abnormal systemic and mucosal 


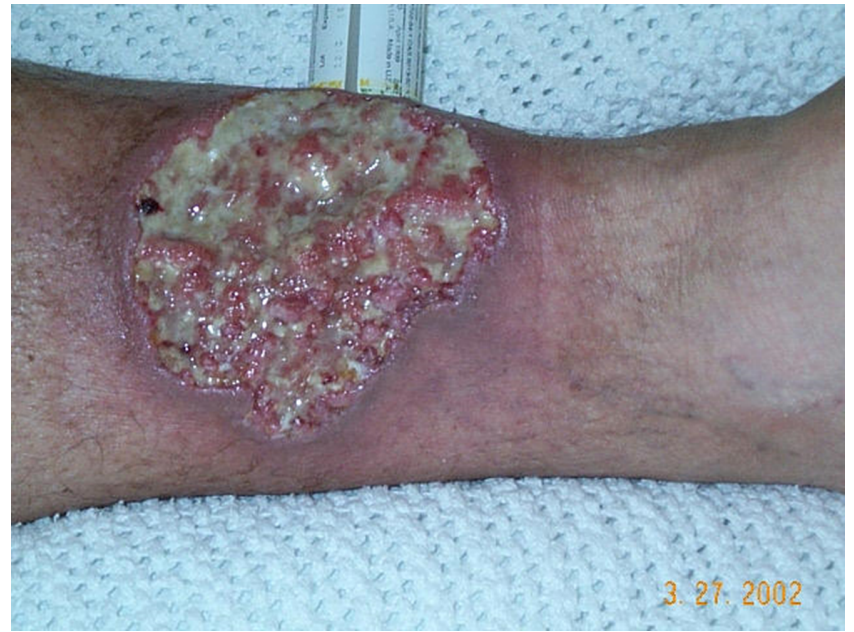

Figure 50.4 Pyoderma gangrenosum affecting the lower leg of a person with $\mathrm{CD}$. This is a condition that causes tissue to become necrotic, resulting in deep ulcers that usually occur on the legs. Ulcers usually initially look like small bug bites or papules and then progress to larger ulcers. While the ulcers rarely lead to death, they can cause pain and scarring. Although the etiology is not well understood, the disease is thought to be due to immune system dysfunction, and particularly abnormal functioning of neutrophils. The commonest diseases associated with pyoderma gangrenosum are the IBDs (CD and UC), followed by the arthritides such as rheumatoid arthritis, followed by malignant hematological disorders. (See color plate section.) Source: http://commons.wikimedia.org/wiki/File:Crohnie_Pyoderma_ gangrenosum.jpg\#file.

immune response against intraluminal antigens, favored by microbial factors [7] and alteration of the mucosal barrier [8]. A key role in the pathogenesis of IBD seems to be played by enhanced proliferation and defective apoptosis of immune cells, attributed to an imbalance of the antiapoptotic protein BCL-2 and the pro-apoptotic protein BAX $[9,10])$, as well as by proinflammatory cytokines arising from Thelper cells (Th) 1 and Th17 CD4 $\mathrm{T}$ cell differentiation in $\mathrm{CD}$, and $\mathrm{Th} 2 \mathrm{~T}$ cell differentiation in UC [11-13]. The loss of balance between proliferation and apoptosis is responsible for the presence of an abnormal population of $\mathrm{T}$ cells with extended lifespan, which remains in the mucosal compartment and secretes proinflammatory cytokines. The result is an activation of other inflammatory cells, including macrophages and B cells, and a recruitment of circulating leukocytes into the gut through interactions between homing receptors (e.g., $\alpha_{4} \beta_{7}$ integrin) and addressins on vascular endothelium, such as the mucosal vascular addressin cell adhesion molecule (MAdCAM)-1 or the vascular cell adhesion molecule (VCAM)-1.

In $C D$ the initial phase of the inflammation seems to be predominantly driven by a Th1 response. Interleukin (IL)-12, a proinflammatory cytokine produced by dendritic cells (DCs), promotes the conversion of $\mathrm{T}$ cells into Th1 cells, secreting interferon (INF) $-\gamma$ and tumor necrosis factor (TNF)- $\alpha$, two major actors in the induction and propagation of inflammation [14-18]. In a later phase, the importance of the Th17 response increases. Th17 cells are induced by IL- 6 and transforming growth factor (TGF)- $\beta$, and secrete IL-17 and IL-22. IL-23, produced by DCs, interacts with Th17 cells and increases the secretion of IL- 6 and IL-17 by T cells, thus enhancing the inflammatory response [19-24]. This overactive immune response can lead to the development of mucosal lesions. Defective apoptosis also promotes autoimmunity, by a reduced autoantibody clearance. Interestingly, almost all drugs with clinical efficacy, including infliximab [25], are able to induce apoptosis of immune cells in vitro, while etanercept, an anti-TNF-fusion protein that does not induce apoptosis of immune cells [26], is not efficacious in the treatment of CD [27]. Nevertheless, certolizumab pegol, another anti-TNF agent, is unable to induce cell apoptosis [28], and yet is effective for inducing and maintaining remission in active CD [29,30]. Eventually, chronic inflammation induces intestinal fibroblasts to proliferate and produce a greater amount of extracellular matrix, resulting in local intestinal fibrosis [31].

Endoscopic appearances are shown in Figure 50.5.

In UC, inflammation is mainly driven by IL- 5 and IL-13, while production of INF- $\gamma$ is normal. The disease is qualified as "Th2like" given the normal production of IL-4, the most defining Th2 cytokine [11]. A Th17 response may also play a role, but its importance is probably lower than in CD.

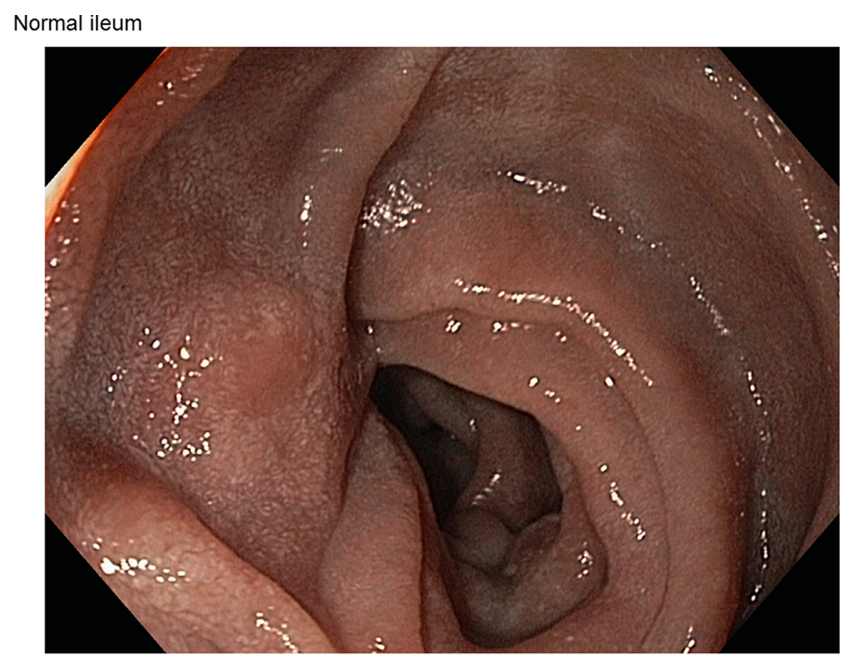

(A)

Figure 50.5 (A) Normal ileum: the mucosa is homogeneously pink and the villi are regular and well developed. (B) Crohn's ileitis: diffuse inflammation characterized by erythema and mucosal hemorrhage. (C) Crohn's ileitis: presence of erythema and ulcers; red dots indicate mucosal hemorrhages. (D) Normal colon: colonic folds are present and regular. The vascular pattern is also readily visible. (E, F) Crohn's colitis: presence of diffuse inflammation with erythema and superficial ulcers. (G) Healed colon. (See color plate section.) 


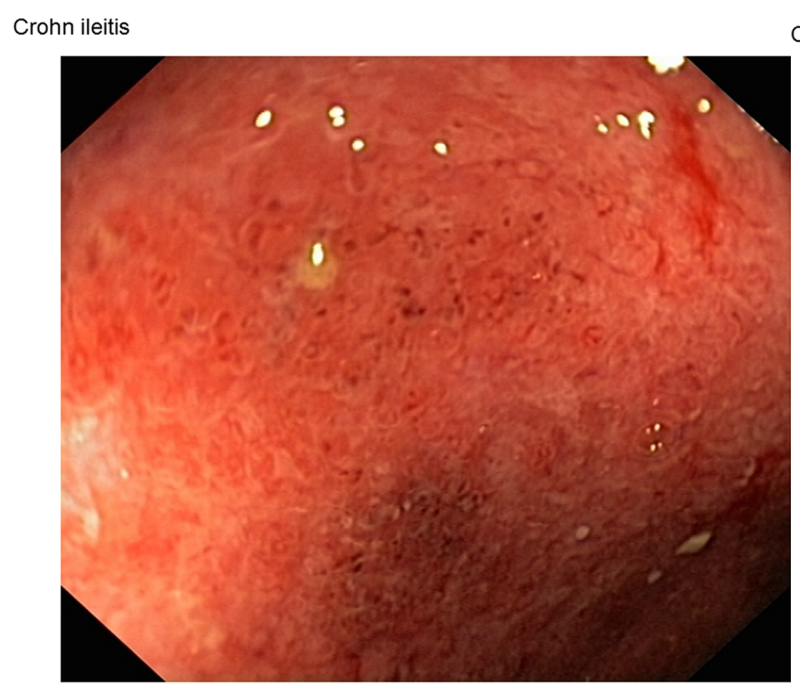

(B)

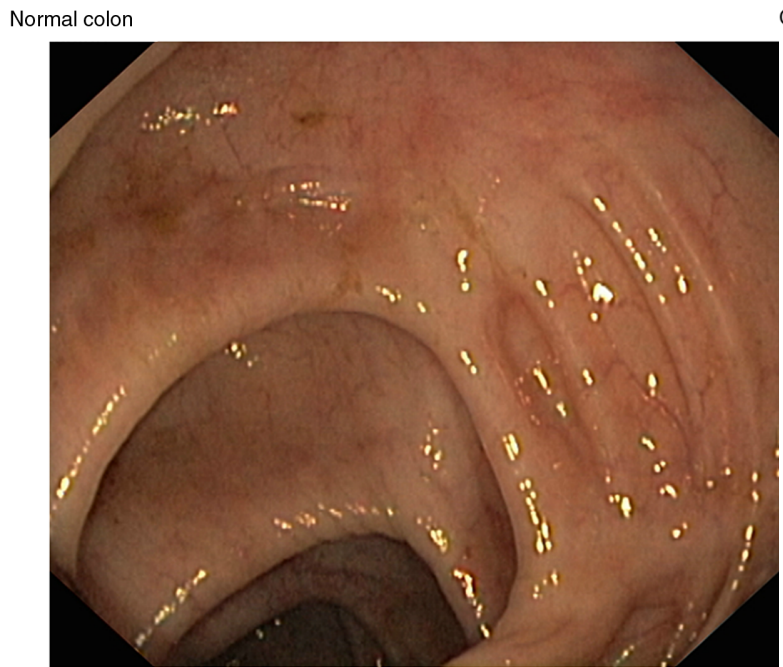

(D)

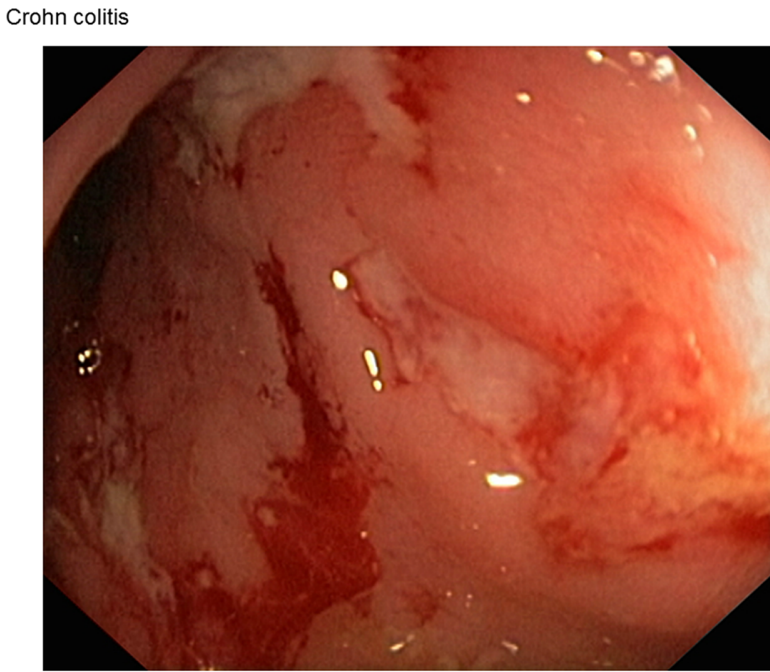

(F)
Crohn ileitis

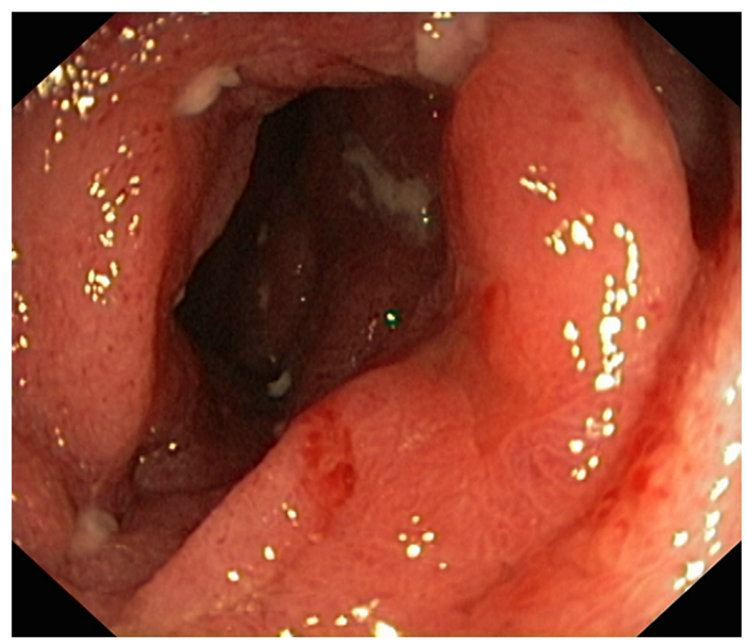

(C)

Crohn colitis

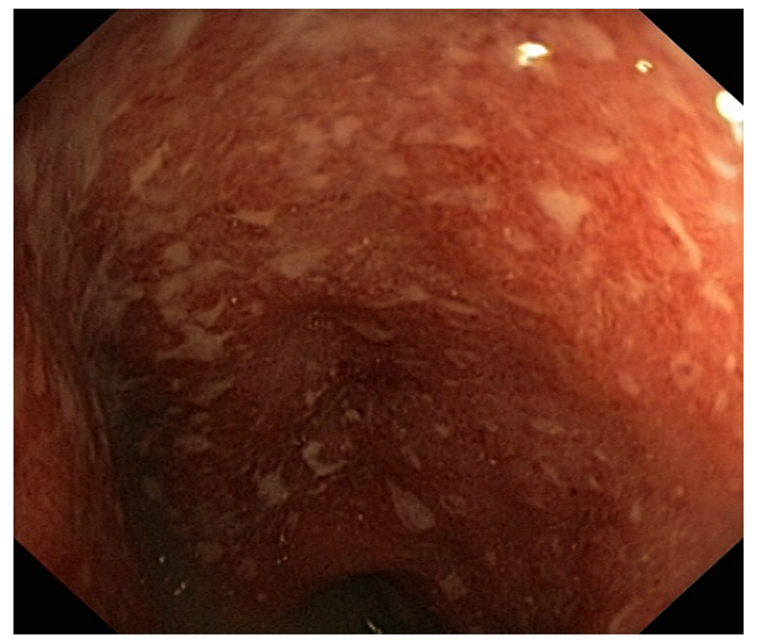

(E)

Healed colon

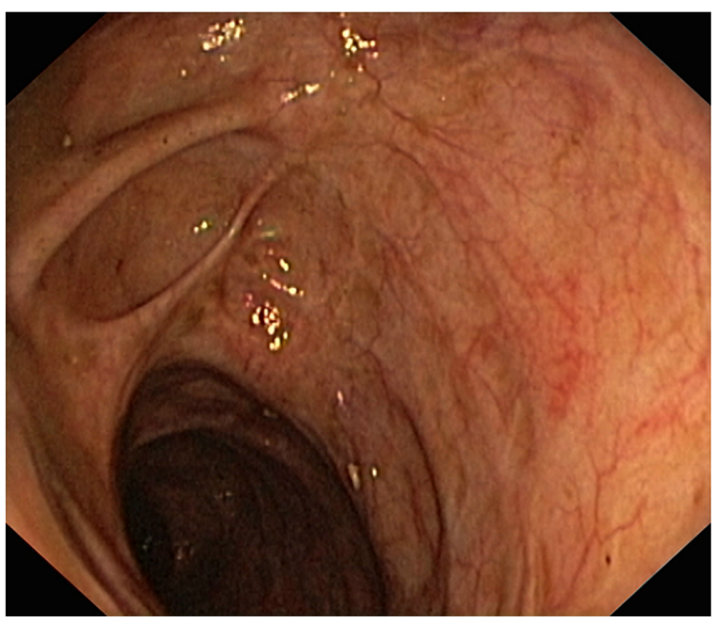

(G)

Figure 50.5 (Continued) 
Table 50.1 The CDAl is a research tool used to quantify the symptoms of patients with CD.

\begin{tabular}{lc}
\hline Clinical or laboratory variable & Weighting factor \\
\hline Number of liquid or soft stools each day for 7 days & $\times 2$ \\
Abdominal pain (graded from 0 to 3 on severity) each day for 7 days & $\times 5$ \\
General wellbeing, subjectively assessed from 0 (well) to 4 (terrible) each day for 7 days & $\times 7$ \\
Presence of complications & $\times 20$ \\
Taking Lomotil or opiates for diarrhea & $\times 30$ \\
Presence of an abdominal mass (0 as none, 2 as questionable, 5 as definite) & $\times 10$ \\
Hematocrit of $<0.47$ in men and $<0.42$ in women & $\times 6$ \\
Percentage deviation from standard weight & $\times 1$ \\
\hline
\end{tabular}

Source: Best et al. [32].

Remission of CD is defined as CDAl below 150. Severe disease is defined as a value of greater than 450 .

${ }^{a}$ One point each is added for each set of complications: (a) the presence of joint pains (arthralgia) or frank arthritis; (b) inflammation of the iris or uveitis; (c) the presence of erythema nodosum, pyoderma gangrenosum, or aphthous ulcers; (d) the presence anal fissures, fistulae, or abscesses; (e) the presence of other fistulae; (f). Fever during the previous week.

\subsection{Treatment of Crohn's disease}

The choice of therapy is based on anatomic location, severity, and behavior of disease. Severity can be assessed by the CD activity index (CDAI), a score based on daily symptoms and repercussions of $\mathrm{CD}$ such as hematocrit, weight, and other factors (Table 50.1).

$\mathrm{CD}$ can be classified as mild or mild-moderate (CDAI between 150 and 220), moderate or moderate-severe (CDAI between 220 and 450), or severe or severe/fulminant (CDAI $>450)$. There is a current trend to use CRP levels in conjunction with the CDAI to evaluate severity of the disease $[4,33]$. Disease remission is defined in the majority of clinical trials as a CDAI of less than 150 [34]. Response is often defined by a variation of CDAI of 100 points or more, although a variation of 70 points or more has been used in some studies. The perineal disease activity index (PDAI) is sometimes used if perineal lesions are predominant. Endoscopic evaluation can be standardized using the $\mathrm{CD}$ endoscopic index of severity (CDEIS) or a simplified variant, the simple endoscopic score for CD (SESCD) [35].

\subsubsection{Current treatment options for Crohn's disease}

Current treatment strategies include oral 5-aminosalicylates (sulfasalazine, mesalamine), antibiotics (metronidazole, ciprofloxacin), topically or systemically acting steroids (controlled ileal release budesonide or prednisone), and immunomodulator therapy, including azothioprine, 6-mercaptopurine, methotrexate, calcineurin inhibitors (cyclosporine, tacrolimus) and antiTNF antibodies (infliximab, adalimumab, certolizumab pegol). Nutritional therapy (elemental or polymeric diets) can be considered as an adjunct treatment. Mildly to moderately active localized ileocecal disease can often be managed with budesonide, while severe active or extensive disease generally requires systemic corticosteroids with or without an immunomodulator. Anti-TNF therapy, used alone or in adjunction to an immunomodulator, is recommended in moderate to severe or extensive relapsing disease or in previously steroid-refractory, -dependent, or -intolerant patients. All currently available anti-TNF therapies appear to have similar efficacy.

If there is loss of response to anti-TNF therapy, increasing doses or frequency of administration can be tried before switching to another anti-TNF agent. Surgery should be considered in localized disease. Treatment of relapse is essentially based upon previously successful therapies, but other factors such as patient preference, time to relapse, concurrent therapy, and adherence to therapy are taken into account. The choice of maintenance therapy is essentially based upon the course and extent of disease, and the effectiveness and tolerance of previously used treatments. Some patients do not need maintenance. Azathioprine is generally the first choice, followed by methotrexate and anti-TNF therapy [36].

Perianal and fistulizing disease can be treated by surgery, including surgical drainage, fistulotomy and setons, advancement flaps, antibiotics, or an immunomodulator (including antiTNF agents) [33]. A seton or seton stitch is a procedure used to aid the healing of fistulas. The procedure involves running a surgical-grade cord through the fistula tract so that the cord creates a loop that joins up outside the fistula. The cord provides a path that allows the fistula to drain continuously while it is healing, rather than allowing the exterior of the wound to close over. Keeping the fistula tract open can help keep from trapping pus or other infectious material in the wound. The procedure was mentioned by Hippocrates in 400 BC. Flap surgery is a technique in plastic and reconstructive surgery where any type of tissue is lifted from a donor site and moved to a recipient site with an intact blood supply. Advancement flaps are used when the patient is in overall good health and the defect is free of tumor and obvious infection. 


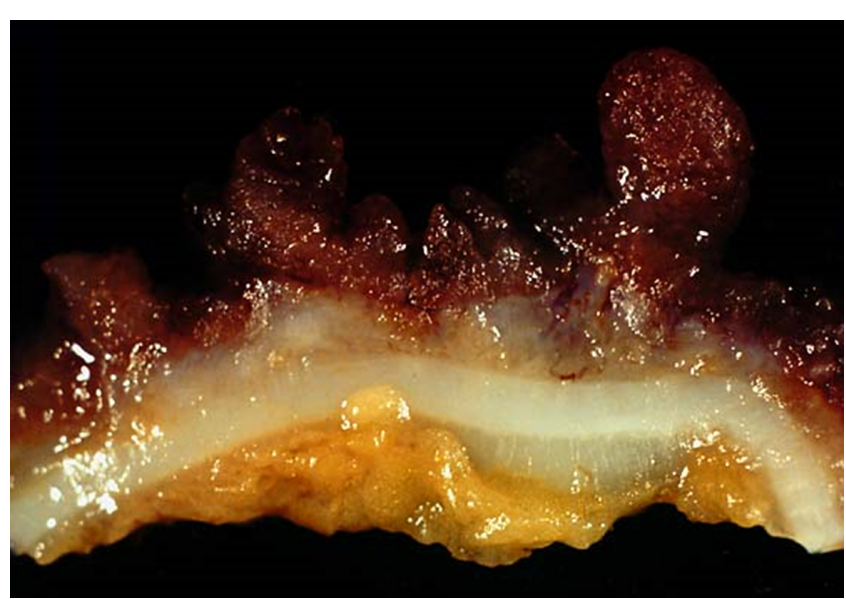

Figure 50.6 Chronic UC. The image shows a view of a longitudinal section through the colon wall. This demonstrates not only the angry red mucosa but also the tendency for the inflamed tissue to throw itself up into inflammatory pseudopolyps. (See color plate section.) Source: http:// commons.wikimedia.org/wiki/File:Chronic_Ulcerative_Colitis_1 .jpg\#mediaviewer/File:Chronic_Ulcerative_Colitis_1.jpg.

Whereas $80-90 \%$ of the patients can be satisfactorily treated with these approaches, some patients are refractory, intolerant, or lose response to them. In this setting, few options are left apart from debilitating surgery with a permanent stoma or experimental treatments. Images of surgical resections are shown in Figures 50.6 and 50.7 .

\subsubsection{Potential treatment options}

New therapies that have demonstrated some efficacy are inhibiting leucocyte migration, targeting inflammatory cytokines, enhancing immune regulatory mechanisms, and/or promoting tissue repair.

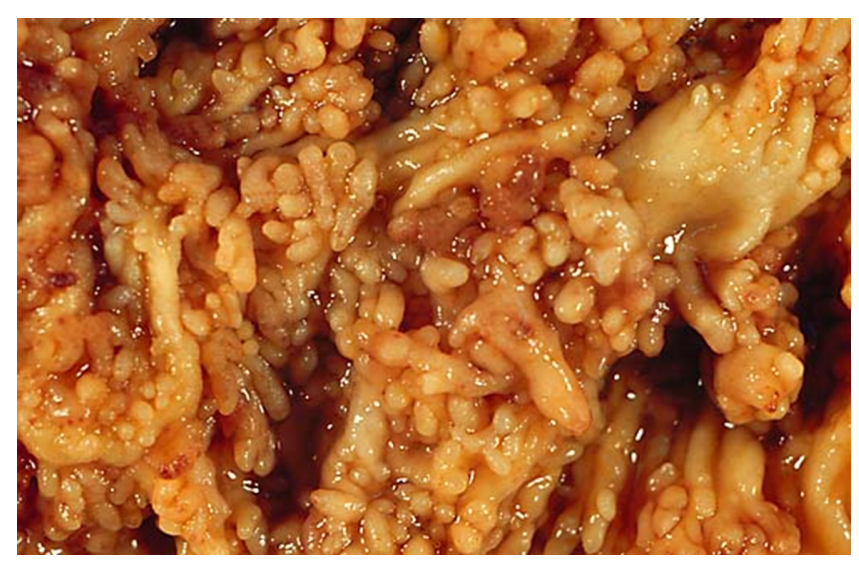

Figure 50.7 Colonic pseudopolyps of a patient with chronic severe intractable UC. Colectomy specimen. (See color plate section.) Source: http://commons.wikimedia.org/wiki/File:Chronic_Ulcerative_Colitis_1 .jpg\#mediaviewer/File:Chronic_Ulcerative_Colitis_1.jpg.

\subsubsection{Drugs targeting leucocyte homing}

Alpha-4 integrins are members of the cell-surface adhesion family expressed by several cells, including leucocytes, and binding several ligands, including VCAM-1 expressed on endothelial cells, and extra-cellular matrix proteins such as fibronectin. These interactions lead to various cellular processes, such as activation, proliferation, and migration of $\alpha_{4}$-integrin-expressing cells toward sites of inflammation, including areas of the gut in CD [37]. Natalizumab, a humanized monoclonal antibody against the $\alpha_{4}$ subunit of both $\alpha_{4} \beta_{1}$ and $\alpha_{4} \beta_{7}$ integrins, has demonstrated therapeutic benefit in patients with moderate to severe active $\mathrm{CD}$. In the ENACT-1 randomized clinical trial (RCT) evaluating natalizumab versus placebo as induction therapy in 905 patients with active $\mathrm{CD}$, similar rates of response (decrease in CDAI of $\geq 70$ points) and remission (CDAI $<150$ ) were observed at week 10 (respectively 56\% versus 49\%, $P=0.05$, and $37 \%$ versus $30 \%, P=0.12$ ). In a second part of the trial (ENACT-2) evaluating natalizumab versus placebo as maintenance therapy in 339 patients who had a response to natalizumab in the first trial, a significantly higher rate of sustained response (61\% versus $28 \%, P<0.001$ ) and remission (44\% versus $26 \%, P=0.003$ ) was observed at week 36 [38]. In ENCORE, an RCT evaluating the efficacy of natalizumab versus placebo as induction therapy in 509 patients with moderately to severely active CD and active inflammation (CRP $>2.87 \mathrm{mg} / \mathrm{L}$ ), significantly higher rates of response (decrease in CDAI of $\geq 70$ points) at week 8 and remission (CDAI $<150)$ were observed (respectively $48 \%$ versus $32 \%, P<0.001$, and $26 \%$ versus $16 \%$, $P=0.002$ ) [39]. In a meta-analysis of five trials comparing natalizumab with placebo, the relative risk (RR) of not achieving remission was reduced with natalizumab (0.88) [40]. In the USA, monotherapy with natalizumab is indicated for inducing and maintaining clinical response and remission in adult patients with moderately to severely active CD and evidence of inflammation who have had an inadequate response or who are unable to tolerate conventional CD therapies and anti-TNF agents [33]. The most dangerous adverse effect is progressive multifocal leukoencephalopathy caused by the JC virus.

Vedolizumab, a humanized anti- $\alpha_{4} \beta_{7}$ integrin monoclonal antibody, has also been approved by the US Food and Drug Administration and the European Medicine Agency for use in patients with moderate to severe $\mathrm{CD}$. In the induction phase comparing intravenous vedolizumab therapy $(300 \mathrm{mg}$ ) versus placebo in 368 adults with active $\mathrm{CD}$, a higher rate of clinical remission $(\mathrm{CDAI} \leq 150)$ was observed $(14.5 \%$ versus $6.8 \%$, $P=0.02)$, while CDAI-100 response was similar (31.4\% versus $25.7 \%, P=0.23)$. In the maintenance phase comparing intravenous vedolizumab therapy every 8 or 4 weeks versus placebo in 461 patients who had had a response to vedolizumab, there was a significantly higher rate of clinical remission $(39.0 \%$ and $36.4 \%$ for the two vedolizumab groups, respectively, versus $21.6 \%$ for the placebo group; $P<0.001$ and $P=0.004)$, but also a higher rate of serious adverse events $(24.4 \%$ versus $15.3 \%)$ and infections (44.1\% versus $40.2 \%$ ) [41]. 
Chemokine receptor 9 (CCR9) is a highly specific receptor expressed predominately by $\mathrm{T}$ cells. Its overexpression leads to the migration of $\mathrm{T}$ cells to the small and large intestines. In PROTECT-1, an RCT with 436 subjects suffering from moderate to severe CD (CDAI between 250 and 450 and CRP $>7.5 \mathrm{mg} / \mathrm{L}$ ), a CCR9 antagonist (CCX282-b/Traficet-EN) given $250 \mathrm{mg}$ twice daily for 36 weeks demonstrated efficacy in maintaining remission in patients identified as responders (decrease in CDAI of $\geq 70$ points) after the induction phase (47\% of subjects on CCX282-B in remission at 36 weeks versus $31 \%$ on placebo; $P=0.01)$. CCX282-B was also superior to placebo in normalizing CRP at week 36 (19\% versus 9\%; $P=0.04)$, and decreasing the number of subjects requiring corticosteroid rescue therapy ( $11 \%$ versus $21 \%, P=0.04$ ). Serious adverse events occurred in similar rates in the two groups [42].

Other molecules targeting $\mathrm{T}$ cells, but not interfering with homing, have been studied with less success. Visilizumab, a humanized monoclonal antibody directed at the cell surface marker CD3 expressed only by activated $\mathrm{T}$ cells, inducing selective apoptosis of these activated T cells, has shown some efficacy in an uncontrolled trial [43] but was associated with an increased rate of adverse events, including cytokine release syndrome and liver toxicity [44].

Cytokine release syndrome is a common immediate complication occurring with the use of anti-T cell antibody infusions such as antithymocyte globulin (ATG), OKT3 (muromonabCD3), and TGN1412, and also with the CD-20 antibody rituximab against B cells. Severe cases are known as cytokine storms. The antibodies bind to the T cell receptor (TCR), activating the T cells before they are destroyed. The cytokines released by the activated $\mathrm{T}$ cells produce a type of systemic inflammatory response similar to that found in severe infections and characterized by hypotension, pyrexia, and rigors. The patient feels very unwell, as if in a high fever - indeed, the cytokine release syndrome is effectively a type of noninfective fever. Deaths due to cytokine release syndrome with OKT3 have been reported, and it can cause life-threatening pulmonary edema if the patient is fluid overloaded. However, if treated appropriately it is usually not dangerous, just extremely unpleasant for the patient.

Abatacept, a CTLA-Ig (cytotoxic T-lymphocyte-associated protein) that blocks the co-activation of $\mathrm{T}$ cells by competing with CD28 for CD80/CD86, and which is used in the treatment of rheumatoid arthritis, was not found to be effective in CD [45].

\subsubsection{Drugs targeting the proinflammatory cascade}

The proinflammatory cytokines IL-12 and IL-23 are involved in Th1 and Th17 responses respectively, and both are implicated in the pathogenesis of $\mathrm{CD}$ [46]. Ustekinumab, a human monoclonal antibody blocking the p 40 common subunit of IL-12 and IL-23, was evaluated in a phase II RCT with 526 adults suffering from moderate-to-severe CD that was resistant to TNF antagonists. In the induction phase, clinical response at 6 weeks was significantly higher in a subgroup of patients receiving $6 \mathrm{mg} / \mathrm{kg}$ of ustekinumab intravenously $(39.7 \%$ versus $23.5 \%$ in the placebo group,
$P=0.005$ ), while there was no significant difference in clinical remission. In the maintenance phase of the trial, comparing $90 \mathrm{mg}$ of ustekinumab subcutaneously versus placebo in 145 patients who had a response to ustekinumab at 6 weeks, significantly increased rates of clinical response $(69.4 \%$ versus $42.5 \%$, $P<0.001)$ and remission ( $41.7 \%$ versus $27.4 \%, P=0.03)$ at 22 weeks [47]. Phase III trials are currently underway to evaluate the safety and efficacy of ustekinumab (www.clinicaltrials.gov; NCT01369355, NCT01369342, NCT01369329).

The proinflammatory cytokine IL- 6 has been implicated in the pathogenesis of colitis in various animal models and in patients with CD $[48,49]$. In a small pilot study with 36 patients suffering from active CD, a biweekly $8 \mathrm{mg} / \mathrm{kg}$ infusion of tocilizumab, an anti-IL-6 receptor humanized monoclonal antibody used in rheumatoid arthritis, showed promising results with $8 / 10$ (80\%) patients experiencing a clinical response compared with $4 / 13(31 \%)$ patients in the placebo group $(P=0.019)$, although only two patients achieved remission. The incidence of adverse events was similar in the two groups [50].

Thalidomide has anti-inflammatory effects, by decreasing the production of proinflammatory cytokines, including TNF- $\alpha$ and IL-12. It appears to be effective in inducing remission in refractory pediatric $\mathrm{CD}$, as shown in a randomized controlled trial with 56 children with active CD despite immunosuppressive treatment (prolonged by an open-label extension of the study, where nonresponders to placebo received thalidomide). Overall, 32/49 (65.3\%) patients treated with thalidomide achieved a response (reduction in pediatric CDAI by $\geq 75 \%$ ) and $31 / 49(63.3 \%$ ) achieved clinical remission [51].

Since IL-17 and IFN- $\gamma$ have been identified as major actors in the pathogenesis of $\mathrm{CD}$, molecules inhibiting these agents have been developed. However, anti-IL-17 antibodies (secukinumab [52], brodalumab [53]) and anti-IFN- $\gamma$ antibodies (fontolizumab [54]) all failed to demonstrate efficacy. Despite encouraging preliminary results, attempts to administer antiinflammatory cytokines, such as IL-10 $[55,56]$ and IL-11 $[57,58]$, were also disappointing, as no significant improvement was observed.

\subsubsection{Other treatments}

Some other treatments have been studied with encouraging preliminary results, including human growth hormone [59], linoleic acid [60], low-dose naltrexone [61], helminths [62,63], or extracorporeal photopheresis [64]. Larger studies are needed to confirm these results. Other agents have so far failed to demonstrate efficacy including granulocyte colony-stimulating factor (G-CSF) and granulocyte-macrophage colony-stimulating factor (GM-CSF) [65,66], probiotics [67-70], and prebiotics [71]. If intestinal failure occurs, home parenteral nutrition and intestinal transplantation can be discussed [72]. Interestingly, several cases of CD recurrence after intestinal transplantation have been reported [73-75], which may indicate that the immune system plays a more important role than the mucosal barrier in the pathogenesis of CD. 


\subsubsection{Bone marrow transplantation and stem cell therapy}

The first reported success of autologous hematopoietic stem cell transplantation (HSCT) in CD was published in 1993 in a patient with non-Hodgkin's lymphoma [76]. Since then, at least 19 cases of autologous or allogeneic HSCTs for malignancies in CD patients have been reported, with remission of $\mathrm{CD}$ achieved in most cases, even after discontinuation of any immunosuppressive therapy [77]. Given these results, HSCT trials in patients with $\mathrm{CD}$ refractory to conventional therapy were initiated. In 1995, the Autoimmune Diseases Working Party of the European Group for Blood and Marrow Transplantation recommended the use of autologous rather than allogeneic HSCT because of the lower risk of severe toxicity [78]. The largest study is a phase I-II trial on 24 patients with severe CD (CDAI >250 and/or Crohn Severity Index $>16$ ) despite anti-TNF therapy, who underwent autologous HSCT after mobilization of their peripheral blood hematopoietic stem cells (HSCs) with cyclophosphamide and G-CSF, ex vivo $\mathrm{HSC}$ enrichment by $\mathrm{CD} 34^{+}$selection, and non-marrow ablative preparation with cyclophosphamide and equine or rabbit ATG.

All patients went into remission (CDAI <150). After 5 years, the percentage of clinical relapse-free survival was $19 \%$ and the percentage of patients in remission, steroid-free, or medicationfree was at least $70 \%, 80 \%$, and $60 \%$ respectively. Infectious complications were frequent, including early bacteremia and/or central venous line infection (six patients) and late infections (10 cases, including seven severe infections, in the first year after transplantation) [79]. A randomized phase III study was initiated, but recruitment was halted prematurely for safety reasons (http://clinicaltrials.gov/ct2/show/NCT00297193). Preliminary results on 48 patients after 1 year follow-up showed decreases in mean CDAI from 324 to 161, CRP from 16.6 to $6.5 \mathrm{mg} / \mathrm{L}$, with six patients achieving a normal CDAI and three patients allowed to stop immune-suppressive medications. However, high rates of adverse events were observed (100 serious adverse events, among which 42 infective episodes requiring or prolonging hospitalization and eight patients with temporary flare of $\mathrm{CD}$ activity or a need for surgery) [80].

\subsection{Treatment of ulcerative colitis}

The choice of therapy is based on the activity, distribution, and pattern of disease. Disease activity can be evaluated by Truelove and Witts' criteria (number of bloody stools/day, pulse, temperature, hemoglobin, and erythrocyte sedimentation rate or CRP) or the Mayo score, and is classified as mild, moderate, or severe. Remission is defined as complete resolution of symptoms and endoscopic mucosal healing. Response is defined as clinical and endoscopic improvement (generally a decrease in the activity index of $>30 \%$, associated with a decrease in the rectal bleeding and endoscopic scores in the Mayo score) [2].

\subsubsection{Current treatment options for ulcerative colitis}

Current treatment strategies include oral 5-aminosalicylates (sulfasalazine, mesalamine), antibiotics (metronidazole, ciprofloxacin), topically or systemically acting steroids (prednisone, beclomethasone dipropionate), and immunomodulatory therapy, including azathioprine, 6-mercaptopurine, calcineurin inhibitors (cyclosporine, tacrolimus), and anti-TNF antibodies (infliximab, adalimumab, golimumab). Surgery (procolectomy with ileo-anal anastomosis) is an option to treat acute severe colitis or to manage refractory disease (see Figures 50.5 and 50.7) [81].

\subsubsection{Potential new treatment options}

The most promising therapies for $\mathrm{UC}$ are essentially acting through an inhibition of leukocyte migration or inflammatory cytokines. Several anti-integrin antibodies have been studied in UC, including vedolizumab [82], which has been recently approved by the US Food and Drug Administration, and etrolizumab, a humanized monoclonal antibody targeting the $\beta_{7}$ subunit of $\alpha_{4} \beta_{7}$ and $\left.\alpha_{E} \beta_{7}\right)[83,84]$ and PF-00547,659, a monoclonal antibody to MAdCAM [85], which have been found effective in preliminary trials.

Alicaforsen, an inhibitor of intracellular adhesion molecule- 1 [86-88], and tofactinib, a Janus kinase- 3 inhibitor [89], have also shown promising results in UC. The roles of methotrexate [90-94], probiotics, and fecal microbiota transplantation $[95,96]$ in the treatment of UC are still debated, and randomized controlled trials are needed to evaluate their effectiveness. Despite encouraging preliminary results, anti-IL-2 receptor (daclizumab [97,98], basiliximab [99-101]) and antiCD3 (visilizumab [102-104]) monoclonal antibodies have failed to demonstrate efficacy in larger trials. Rituximab (an anti-CD20 antibody against $\mathrm{B}$ cells) is ineffective and can even mediate exacerbation of UC [105-107].

\subsection{Properties of mesenchymal stromal cells}

Mesenchymal stromal cells (MSCs) are multipotent progenitors within the bone marrow and all other vascularized organs that are capable of differentiating into various cells and tissues, such as chondrocytes, osteoblasts, and adipocytes in vitro [108]. MSCs can be isolated after ex vivo culture of the plastic-adherent mononuclear cell fraction. After ex vivo expansion human MSCs have a fibroblast-like morphology, and are uniformly positive for CD29, CD44, CD71, CD73, CD90, CD105, CD106, CD120a, CD124, and CD166 but do not express common hematopoietic markers such as CD14, CD45, or CD34. No marker specific for MSCs has been found yet. The International Society for Cellular Therapy has proposed three minimal criteria to define MSCs: (1) adhesion to plastic in standard culture conditions, (2) expression of CD105, CD73, and CD90, and lack of expression of CD45, CD34, CD14 or CD11b, CD79a or CD19, and human leukocyte antigen (HLA)-DR surface 
molecules, and (3) in vitro differentiation into osteoblasts, adipocytes, and chondroblasts [109]. MSCs can be isolated from bone marrow and many other tissues, including umbilical cord [110], umbilical cord blood [111], placenta [112], adipose tissue [113], gingival tissue [114], skin [115], lung [116], liver [117], heart, and spleen [118]. They are pericytes residing in the endothelium in the connective tissues of most organs [119].

\subsubsection{Immunomodulation}

MSCs also exert powerful immunomodulatory effects, including inhibition of proliferation and function of T cells, B cells, and natural killer (NK) cells. These properties have been demonstrated in vitro with both murine and human cells, and in vivo in murine models of experimentally induced colitis. Dextran sodium sulfate (DSS) and trinitrobenzene sulfonate (TNBS) are commonly used to induce colitis in mice, by initiating epithelial cell lesions and altering the epithelial barrier integrity. Both acute DSS- and TNBS-induced colitis are characterized by a Th1-Th17-mediated acute inflammation with increased TNF- $\alpha$, IL-6, IL-17 and increased IL-12, IL-17, IFN- $\gamma$ respectively. However, while chronic TNBS-induced colitis is associated with an enhanced Th1/Th17 intensity of response, chronic DSS-induced colitis switches to a Th2-biased (IL-4, IL-10) profile. Similarly, histological DSS-colitis features are "UClike" (epithelial disruption, focal lesions, superficial inflammation), while histological TNBS-colitis features are "CD-like" (transmural inflammation and edema) [120].

The first observed immunomodulatory effect of MSCs was their ability to inhibit T cell proliferation in vitro [121-123]. This phenomenon was observed independently of whether the T cells were $\mathrm{CD}^{+}$or $\mathrm{CD}^{+}$, naive or memory T cells [124], stimulated with allogeneic cells or nonspecific mitogens [123], and regardless of their functional state or the type of TCR expressed [125]. The immunosuppressive activity of MSCs is independent of the major histocompatibility complex (MHC), as inhibition is similar using third-party MHC-unmatched MSCs or MSCs that are autologous to the responder or stimulating lymphocytes [121]. MSC-inhibited T cells do not undergo apoptosis [123], but are blocked in the $G_{0} / G_{1}$ phase of the cell cycle in a state of anergy by inhibition of cyclin D2 expression [126]. Whether in vitro addition of IL-2 can [122] or cannot [127] reverse this inhibition is controversial. However, a recent study found that the systemic infusion of murine BM-MSCs induced T cell apoptosis via the FAS ligand/FAS pathway, and that $\mathrm{FASL}^{-1-}$ bone-marrowderived MSCs (BM-MSCs) could not ameliorate DSS-induced colitis in mice [128]. Interestingly, it has been demonstrated that FAS-mediated apoptosis is lower in the T cells of people with CD than in control T cells [129]. However, another study demonstrated that in vitro MSCs prevented activation-induced cell death through downregulation of Fas receptor and Fas ligand on TCR-activated T cells [127]. It is important to note that the effect of MSCs on T cells seems dependent on the MSC/T cell ratio: a high $\mathrm{MSC} / \mathrm{T}$ cell ratio exerts strong inhibitory effects, while low MSC/T cell ratios enhance T cell proliferation [130].
Other studies suggest that an important part of MSC-mediated immunomodulation results from the recruitment of immuneregulatory $\mathrm{T}$ cells (Tregs), which can be either $\mathrm{CD} 4^{+} \mathrm{CD} 25^{+}$ FoxP $3^{+}$or $\mathrm{CD}^{+}$from both naive and memory T cells [131-133]. In vivo, MSC-mediated Treg expansion has been observed in several immune-mediated diseases, including experimental autoimmune encephalomyelitis [134], experimental arthritis [135], and type 1 diabetes mellitus [136]. Mechanisms of this T-reg expansion appear multiple and include secretion of soluble factors by MSCs, such as prostaglandin $\mathrm{E}_{2}\left(\mathrm{PGE}_{2}\right)$ and TGF- $\beta 1$ [137-139] or HLA-G [140,141], interaction between MSCs and chemokine ligand 1 and chemokine receptor 8 on T cells [142], and induction of immature DC [143] and monocytes [144] to a regulatory profile. MSC-mediated T cell modulation was observed in several DSS- and TNBS-induced colitis mouse models, treated with intravenous or intraperitoneal injection of human adipose-derived MSCs (ASCs) [145], umbilicalcord-derived MSCs (UCMSCs) [146,147], or BM-MSCs [148]. In these studies, MSCs effectively treated colitis with both a clinical response and histological improvement, showing decreased infiltration of inflammatory cells in the lamina propria. The investigators mostly observed a decreased number of IFN- $\gamma$-producing Th1 cells and higher numbers of $\mathrm{CD} 4^{+} \mathrm{CD} 25^{+}$Foxp $3^{+}$Tregs in mesenteric lymph nodes and the lower colon and systemic levels of Th1 and Th17 proinflammatory cytokines, including TNF- $\alpha$, IFN- $\gamma$, IL6, IL-12, IL-17, and IL-23, as well as higher colonic and systemic levels of the anti-inflammatory/regulatory cytokine IL-10. In a murine model of TNBS-induced colitis, MSCs colocalized with $\mathrm{CD}_{11} \mathrm{~b}^{+}$cells in the spleen, and these cells were essential to the expansion of Tregs in draining mesenteric lymph nodes [149]. In another murine model of TNBS-induced colitis, intravenous injection of murine BM-MSCs was followed not only by downregulation of both Th1 and Th17 responses and activation of regulatory $\mathrm{T}$ cells, but also by a significant upregulation of Th2 activities (IL-4, IL-10, GATA-3) [150].

The effect of MSCs on B cells remains controversial, and may depend on environmental signals. According to most authors, MSCs inhibit B cell activation, proliferation, chemotaxis, and immunoglobulin $\mathrm{G}$ secretion, both in murine $[126,151,152]$ and human [153] studies. In these studies, B cells were enriched from the spleen or purified from peripheral blood and were exposed to various stimuli, including allogeneic cells, mitogenic agents and lipopolysaccharide. Inhibition of B cell function was mediated by soluble factors in transwell experiments. In another study, B-cell co-stimulatory molecule expression and cytokine production seemed unaffected by human MSCs [153]. However, in a study of highly purified B cells, MSCs promoted proliferation and differentiation into immunoglobulin-secreting cells of naive $B$ cells isolated from healthy donors and total B cells from children with the autoimmune disease systemic lupus erythematosus (SLE), stimulated with an agonist of toll-like receptor (TLR) 9 in the absence of B cell receptor triggering [154].

The relationship between MSCs and NK cells is complex and also not yet fully understood. MSCs inhibit the IL-2- or 
IL-15-driven proliferation of human resting NK cells and their production of IFN- $\gamma$, TNF- $\alpha$, and IL-10 [155,156], but their effects on the cytotoxic activity of NK cells is controversial. Some authors report have reported MSC-mediated decreased NK cell cytotoxicity [140,156,157], while others have not observed this effect $[158,159]$. This discrepancy might depend on MSC/NK ratios or on whether NK cells were freshly isolated or not [155].

MSCs also interact with antigen-presenting cells, including DCs. MSCs inhibit differentiation of DC precursors, such as monocytes or $\mathrm{CD}_{3} 4^{+}$hematopoietic progenitors into mature DCs, by blocking them in the $G_{0} / G_{1}$ phase of the cell cycle, through a downregulation of cyclin D2 and p27 $7^{\text {Kip1 }}$ expression [160]. DCs cultured with MSCs have impaired antigenpresenting [161] and migration [162] functions and show increased secretion of IL-10 and decreased production of IL-12 [163]. These effects have been confirmed in vivo in murine models [164]. MSCs also induce DC precursors (CD34 ${ }^{+}$hematopoietic progenitors) [165] and mature DCs [166] to differentiate into a regulatory DC population through the Notch signaling pathway.

MSCs may also modulate the functions of macrophages, for example, through increased IL-10 secretion [167] or induction into a regulatory-like profile [144]. In vitro addition of increasing numbers of monocytes or DCs into co-cultures of human ASCs and activated $\mathrm{CD} 4^{+}$cells progressively inhibited $\mathrm{T}$ cell proliferation and IFN- $\gamma$ production [145]. In murine models of DSS- and TNBS-induced colitis, the intraperitoneal injection of murine bone marrow macrophages co-cultured with ASCs was effective in treating both colitis and sepsis. In vitro these macrophages showed a regulatory phenotype that was different from activated macrophages and characterized by high arginase activity and increased expression of IL-10 and inducible nitric oxide synthetase (iNOS) upon restimulation with lipopolysaccharide, while secreting low levels of the inflammatory cytokines TNF- $\alpha$ and IL-12. They showed potent immunosuppressive activity on splenocytes that was significantly reversed by the iNOS inhibitor L-NG-nitroarginine methyl ester and IL-10-blocking antibodies [168].

Thus the mechanisms of MSC-mediated immunomodulation are not yet fully elucidated and probably vary among species [169]. They include direct cell-to-cell contact through the expression of adhesion molecules and secretion of soluble factors. Multiple factors are involved, including $\mathrm{PGE}_{2}[156,167,170]$, indoleamine 2,3-dioxygenase $[114,156,171]$, nitric oxide $[172,173]$, HLAG [140,174], TGF- $\beta$ and hepatocyte growth factor [123], IL-1 receptor antagonist [175], TNF-stimulated gene 6 protein [176], and IL-10, which, although probably not secreted directly by MSCs, also participates in the immunosuppressive effect of MSCs, as IL-10 blockade partially reversed the colitis and sepsis in the murine model [145]. In the DSS murine models of DSS- or TNBSinduced colitis, $\mathrm{PGE}_{2}$ produced by nucleotide-binding oligomerization domain-containing protein-2-activated human UCMSCs increased production of IL-10 and Tregs and was required to reduce the severity of colitis [177].
Transcriptional repression of the proinflammatory cytokine early $\mathrm{T}$ cell activation factor 1 (osteopontin) by the autoimmune regulator (AIRE) has also been implicated in MSC immunomodulation as it was required for the efficacy of BM-MSC administration in a model of chronic colitis by transfer of $\mathrm{CD}^{+}$ $\mathrm{CD} 45 \mathrm{RB}^{\mathrm{hi}} \mathrm{T}$ cells in $\mathrm{Rag}^{-1-}$ mice. However, AIRE did not control MSC suppression of $\mathrm{T}$ cell proliferation in vitro [178].

The immunomodulatory effects of MSCs depend on the inflammatory environment and in some circumstances MSCs can act as immune-stimulating cells. TLRs have an important role in inducing MSCs into an immunosuppressive or immunostimulating pathway, as different TLR agonists influence MSC proliferation, differentiation, migration, and immunomodulatory functions in different ways [179-181]. Many inflammatory cytokines promote MSC-mediated immunosuppression, including IFN- $\gamma$, TNF- $\alpha$, and IL-1 $\beta$ [173]. Pretreatment of human BMMSCs with IFN- $\gamma$ increased expression of MHC class II molecules, indoleamine 2,3-dioxygenase, and iNOS and significantly inhibited peripheral blood mononuclear cell (PBMC) proliferation at lower PBMC: MSC ratios. In murine models of DSS- and TNBS-induced colitis, intraperitoneal administration of INF- $\gamma$-pretreated MSCs was more effective in treating colitis, in reducing serum amyloid A levels, in reducing colonic inflammatory cytokines (TNF- $\alpha$, IL-6, IFN- $\gamma$, and IL-17A), and in increasing migration into inflamed intestine [182]. Similarly, IL-1 $\beta$-primed human UCMSCs significantly attenuated the development of DSS-induced murine colitis, increased the number of peritoneal M2 macrophages and splenic or mesenteric lymph node Tregs, and enabled migration more efficiently into the spleen, mesenteric lymph nodes, and colon, which was related to upregulation of CXCR4 expression. IL-1 $\beta$ stimulation elevated COX-2, IL-6, and IL-8 mRNA expression in MSCs [183].

\subsubsection{Immune tolerance}

Human MSCs are immunoprivileged cells because they express low levels of HLA class I molecules and do not express HLA class II molecules nor the co-stimulatory molecules CD80, CD86, and CD40 under normal circumstances $[184,185]$. However, expression of HLA class I antigens, even at a low level, may be responsible for vulnerability of MSCs to activated NK-cell lysis [186]. Moreover, a recent study observed the capacity of murine MSCs to present extracellular antigen through their MHC class I molecules by cross-presentation and to induce an effective $\mathrm{CD} 8^{+} \mathrm{T}$ cell immune response [187]. In addition, it has been demonstrated in vivo that, in the presence of a narrow window of IFN- $\gamma$, MSCs upregulate expression of MHC class I and II molecules and are able to act as antigen-presenting cells and stimulate $\mathrm{CD} 4^{+}$cell proliferation [188-190]. This immunogenicity has also been observed in vivo in animal models in which donor-derived MSCs, unlike autologous MSCs, could promote bone marrow [191] or skin graft [192] rejection. Systemic or local administration of allogeneic MSCs in rats resulted in the development of anti-donor $\mathrm{T}$ cell and antibody responses, which could 
promote a rapid clearance of MSCs and a limitation of their longterm benefits $[193,194]$.

\subsubsection{Tissue regeneration}

MSCs can differentiate in vitro to cells of the mesenchymal lineage. The relative importance of this property for the efficacy of MSCs in experimental colitis and IBD is still being investigated.

\subsubsection{Homing}

MSCs are able to selectively home to sites of tissue injury and inflammation, including intestine, kidney, lung, liver, thymus and skin [195] (and see Chapters 22-24). In murine models of colitis, MSCs have demonstrated their ability to migrate selectively into inflamed zones of the intestine, mesenteric lymph nodes, and spleen, whether they were murine or human, bone marrow, adipose, or umbilical cord derived, and whether administered intravenously or intraperitoneally $[145,147-149,196]$. MSCs have been found in the lamina propria [196], the muscular layer, and the submucosa of the inflamed intestine [197]. However, homing capacities may be altered in MSCs that have been cryopreserved. In a murine model of TNBS-induced colitis, intraperitoneally but not intravenously injected cryopreserved MSCs were found in the inflamed colon [197]. MSC migration is directed by a multitude of signals depending on the MCS source, type or environment, and growth factors and cytokines involved $[198,199]$. In order to better understand the selective migration of MSCs into the inflamed intestine, Gonzalez-Rey et al. [145] studied the expression of various chemokine receptors involved in cell recruitment to inflammatory sites and demonstrated that human ASCs expressed on their surface the chemokine receptors CCR1, CCR2, CCR4, CCR5, CCR7, CCR9, CXCR1, and CXCR5 and that most of these receptors were functional since human ASCs migrated in response to chemokines such as CCL5, CCL22, CCL19, CCL25, CXCL8, and CXCL13. Moreover, human ASCs expressed a panel of adhesion molecules involved in tissue transmigration, including CD54, CD49e, CD44, CD29, CD105, CD106, and CD166. Activation and targeting may improve delivery of MSCs into mesenteric lymph nodes and colon, and hence their efficacy in murine colitis, as demonstrated with IFN- $\gamma-[182]$ or IL-1 $\beta$-primed MSCs [183] and VCAM antibody-coated MSCs (AbVCAM-1MSCs) [200]. IFN- $\gamma$ upregulates expression of the chemokine receptor CXCR7, lectins LGALS3BP and LGALS9 and ADAM15, a matrix metalloproteinase involved in epithelial adhesion [182], while IL-1 $\beta$ upregulates CXCR4 expression [183]. How long MSCs do stay into the inflamed intestine is unknown, but it seems that they remain there for at least 2 weeks [147].

\subsubsection{Differentiation and stimulation of tissue repair}

In addition to their capacity to differentiate into chondrocytes, osteoblasts and adipocytes, MSCs can also differentiate into other cells of the mesenchymal lineage, such as myoblasts [201] or cardiomyocytes [202]. Moreover, UCMSCs [203] and BMMSCs have shown an ability to differentiate in vitro into cells of ectodermal lineage, such as neuroglial cells [204,205], and of endodermal lineage, such as renal tubular epithelial cells [206] and hepatocytes [207-209], although this a controversial area; and while MSCs may take on the morphological and even the cell surface markers of, for example, neurons, there is little, if any, evidence that they function as neurons. This not to say that they are not beneficial in the treatment of diseases involving damaged neurons, but they most likely mediate this effect by secretion of paracrine factors and by modulation of the inflammatory reaction.

As indicated earlier, in response to inflammation or tissue injury, MSCs are capable of engrafting in many tissues [210], albeit transiently, and have demonstrated their efficacy in promoting tissue repair in myocardial infarction [211], kidney diseases [212,213], liver diseases [214], lung diseases [215] and injury [216], and neurological disorders [217]. In DSSinduced colitis in rats, intravenous injection of rat MSCs enabled significant healing of epithelial injuries, and the MSCs extracted from the lamina mucosa had upregulated their expression of $\alpha$-smooth muscle actin, suggesting a reprogramming to myogenic lineage differentiation, possibly involved in intestinal repair. In TNBS-induced colitis in rats, topical implantation of rat BM-MSCs healed mucosal injuries. MSCs engrafted into the submucosal layers, but only a small proportion was positive for $\alpha$-smooth muscle actin and desmin, indicating differentiation into myofibroblasts. A larger proportion of MSCs surrounding the lesion area expressed vascular endothelial growth factor and TGF- $\beta 1$, two growth factors known to play important roles in gastrointestinal wound healing [218]. In a DSS-induced colitis model in rats, intravenous injection of allogeneic MSCs resulted in clinical improvement with markedly reduced epithelial injury and, significantly, restoration of expression of claudin-2, -12 and -15 , proteins constituting tight junctions that play a major role in the paracellular permeability of the epithelial barrier [219].

Again, as indicated earlier, it is thought that the tissue repair properties of MSCs are mainly due to their ability to stimulate survival and recovery of local tissues, rather than to transdifferentiation ability [220]. MSCs have demonstrated their ability to stimulate angiogenesis [221] and to inhibit apoptosis and fibrosis in injured tissues [222].

\subsection{Mesenchymal stromal cell administration in inflammatory bowel diseases}

Two different applications of MSCs in IBDs have been evaluated in human trials: local injection of MSCs to treat fistulizing CD and intravenous injection of MSCs to treat luminal CD or UC. MSC administration has been studied in CD more than it has in UC. 


\subsubsection{Mesenchymal stromal cell administration for fistulizing Crohn's disease}

Management of fistulas in patients with $\mathrm{CD}$ is an extremely challenging problem, because many such fistulas do not respond to available treatment, despite recent improvements using antiTNF agents and improvements in surgical treatments. Endoanal advancement flap is the standard surgical technique, but anal incontinence and recurrence are not uncommon. Several trials have evaluated the efficacy of local injections of ASCs or BM-MSCs.

\subsubsection{Autologous mesenchymal stromal cell administration for fistulizing Crohn's disease}

50.6.2.1 Adipose-tissue-derived mesenchymal stromal cells

In a phase I study García-Olmo et al. treated four patients with one or more refractory, complex Crohn's fistulas with a single intrafistular injection of MSCs. The fistulas were enterocutaneous, suprasphincteric, and/or rectovaginal fistulas, were unresponsive to medical treatment, and had been unsuccessfully treated by surgery at least twice. The injection consisted of $3-30 \times 10^{6}$ autologous ASCs from passages 1 to 3 . Six of eight (75\%) fistulas had healed 8 weeks after treatment, and the other two $(25 \%)$ were incompletely closed with decreased output flow. No relationship was found between the number of injected MSCs and the success of the treatment. No adverse effects were observed within 12-22 months follow-up, and no aberrant differentiation was seen in biopsies [223].

In a phase IIb study the same group showed that ASCs were effective in healing $69 \%$ of complex perianal fistulas in patients with moderate to severe CD who were intolerant or resistant to the anti-TNF agent infliximab [224]. Forty-nine patients with complex perianal fistulas were included. Thirty-five of the fistulas were of cryptoglandular origin and 14 were associated with CD. Cryptoglandular anal fistulas arise from inflammation of the proctodeal glands of the intersphincteric space. The mucus secretions of the anal glands empty into the anal crypts, thereby lubricating the anus. Anal glands are present in the subepithelium and the internal sphincter, with a large number also deeply sited within the intersphincteric space. Infection of these intersphincteric glands is thought to give rise to an intersphincteric abscess if the draining duct is blocked by the resulting infectious debris. The abscess may resolve by spontaneous drainage into the anal canal or it may progress to an acute anorectal abscess that, in most cases, subsequently develops into a perianal fistula. This type of fistula is not associated with CD.

Patients were randomly assigned to the administration of an intrafistular injection of fibrin glue or fibrin glue containing 20 million ASCs. If fistula healing had not occurred by 8 weeks, a second double dose of ASCs was administered. Fistula healing was observed in 17/24 patients receiving ASCs (71\%); 11 patients healed after the first injection and six patients healed after a second injection compared with 4/25 (16\%) in the control group (RR 4.43, $P<0.001$ ). A similar proportion was observed in the $\mathrm{CD}$ patients, with healing of the fistula in five out of seven patients receiving ASCs compared with one out of seven patients in the control group ( $\mathrm{RR} 5.00, P=0.10)$. Improvement of quality of life, assessed by a quality-of-life questionnaire, was significantly greater in the ASC group compared with the control group, even in patients whose fistula did not heal [225]. After an average long-term follow-up of approximately 40 months, 7 out of 12 patients treated with ASCs remained free of recurrence compared with two out of three in the control group. Perianal sepsis occurred more frequently in the control group than in the ASC group $(P=0.04)$. No adverse effects related to ASC administration were noted, confirming their excellent safety and tolerability profile, and no patient suffered from anal incontinence [226].

Another group performed a dose-escalation phase I study, in which 10 patients with a perianal fistula associated with CD were treated with an intrafistular injection of autologous ASCs from passages 3 and 4 at a dose of either $1 \times 10^{7}$ (group 1), $2 \times 10^{7}$ (group 2), or $4 \times 10^{7} \mathrm{ASCs} / \mathrm{mL}$ (group 3). The doses used were selected with regard to the size of the fistula. Eight weeks after injection, complete healing occurred in two out of four patients in group 2 and one out of three patients in group 3, while partial closure with no output drainage was observed in all other patients. After follow-up of 8 months the three patients whose fistula had been completely healed were free of recurrence and no adverse effects were observed [227]. The same group subsequently led a phase II trial studying the effects of the intrafistular injection of ASCs from passages 3 and 4 in 43 patients with perianal fistulas associated with $\mathrm{CD}$. The first injection again contained a number of ASCs that was proportional to the size of the fistula: $3 \times 10^{7}$ ASCs per $1 \mathrm{~cm}$ length of fistula when the fistular diameter was less than $1 \mathrm{~cm}$, and $6 \times 10^{7}$ ASCs per $1 \mathrm{~cm}$ length of fistula when the diameter was between 1 and $2 \mathrm{~cm}$. The average number of ASCs was $15.8 \times 10^{7}$ cells per fistula. Patients without complete fistula closure at 8 weeks received a second injection of 1.5 times more cells than the first injection. The fistula tract was filled with a mixture of ASCs and fibrin glue. Complete fistula healing was observed in $27 / 42$ patients $(64.3 \%)$ by 8 weeks after the final ASC injection and was sustained after 1 year in 23/26 patients (88\%). Six other patients showed incomplete closure of the fistula, of which five patients achieved closure of more than $50 \%$ of the fistula tract with a decrease in drainage of more than $50 \%$. Five other patients discontinued the study before week 8 . No relation was found between the outcome of the treatment and fistula type, length, or diameter or duration of CD. No adverse events related to ASCs were observed [228].

\subsubsection{Bone marrow-derived mesenchymal stromal cells}

The safety and efficacy of serial intrafistular injections of autologous BM-MSCs in the treatment of fistulizing CD was studied by 
Ciccocioppo et al. in 10 patients refractory to all previous medical treatments including anti-TNF agents or unsuccessfully treated by surgery. They administered intrafistular injections of $15-30 \times 10^{6}$ MSC from passage 3 every 4 weeks until improvement was obtained or when autologous MSCs were no longer available Patients received between two and five injections. Sustained complete closure of the fistula tract occurred in $7 / 10$ patients and incomplete closure in $3 / 10$ patients as assessed by surgical exploration and MRI. MRI provided images of regenerative tissue without fibrotic tissue. All patients had a significant reduction of their CDAI scores: pre- and posttreatment median values were $294 \pm 49$ and $99 \pm 32$ at 12 months after the last procedure $(P<0.001)$. Their median PDAI scores pre- and posttreatment were $13.0 \pm 2.2$ and $4.5 \pm 2.4$ at 12 months after the last procedure $(P<0.001)$. Patients who achieved remission had CDAI scores $\leq 150$ and PDAI scores $\leq 8$, usually after the second administration of ASCs. Lower endoscopic examination performed at the end of the follow-up period demonstrated rectal mucosal healing in seven out of seven patients. In addition, they observed a significant increase in the percentage of circulating $\mathrm{CD}^{+}{ }^{+} \mathrm{CD} 25^{\text {bright }} \mathrm{FoxP}^{+}$Tregs as soon as after the second injection of ASCs which was stable at 12 months $(P<0.01)$. Additionally, mucosal FoxP ${ }^{+}$Tregs were present in the inflamed areas at 12 months $(P<0.0001)$. There were no adverse effects during the procedure nor during the 12-month follow-up period [229].

\subsubsection{Allogeneic mesenchymal stromal cell administration for fistulizing Crohn's disease}

García-Olmo and co-workers also explored the use of expanded allogeneic ASCs for the treatment of complex perianal fistulas in patients with nonactive luminal CD $(\mathrm{CDAI} \leq 200)$ in a singlearm multicenter phase I/IIa clinical trial. Twenty-four patients received an intrafistular treatment with $20 \times 10^{6}$ allogeneic ASCs followed by a second administration of $40 \times 10^{6}$ ASCs if fistula closure was incomplete after 12 weeks. After 12 weeks, 12/20 patients $(60.0 \%)$ had an improvement of at least one of their fistulas and complete closure occurred in 8/21 (38.1\%) on clinical examination. After 24 weeks, these values were respectively $9 / 13$ patients $(69.2 \%)$ and $9 / 16$ patients $(56.3 \%)$. Based on a combination of clinical and MRI assessment, fistula closure was seen in $6 / 24$ patients $(30 \%)$ at 24 weeks. A statistically significant decrease in the MRI score of severity was observed at week 12 . PDAI significantly decreased by more than $37 \%$ compared with baseline $(P<0.01)$. No effect was observed on the CDAI scores. Luminal relapse was observed in $0 / 24$ patients $(0.0 \%)$ at week 12 and in $5 / 24$ patients $(20.8 \%)$ at week 24 . After a 6-month follow-up period the safety profile was acceptable, with a low number of serious adverse events: anal abscess in three patients, pyrexia in one patient, and uterine leiomyoma in one patient [230].

\subsubsection{Autologous mesenchymal stromal cell administration for luminal inflammatory bowel diseases}

Intravenous injections of autologous BM-MSCs have been tested in a phase I trial. Nine adult patients with moderate to severe CD with a CDAI score between 220 and 450 and who were refractory to conventional standard treatment, including corticosteroids, immunosuppressive agents, or anti-TNF therapy, were treated with two intravenous injection of $1-2 \times 10^{6}$ cells $/ \mathrm{kg}$ body weight 7 days apart. Three patients had a clinical response (defined as a decrease in CDAI score of $\geq 70$ points) but none achieved remission (CDAI <150), and four patients experienced worsening of their disease, requiring surgery in three cases or rescue medication in one case within 14 weeks after BM-MSC administration. Endoscopic improvement using the SESCD was seen in two patients at week 6 . Biopsies of inflamed mucosa showed a trend to lower $\mathrm{CD}^{+} \mathrm{T}$ cell and higher $\mathrm{CD} 4^{+} \mathrm{CD} 127^{+}$Treg numbers [231]. CD127 is the receptor for IL-7.

\subsubsection{Allogeneic mesenchymal stromal cell administration for luminal inflammatory bowel diseases}

Intravenous injection of allogeneic BM-MSCs has also been evaluated with more success in a phase II pilot study. Nine patients with refractory moderate-to-severe $\mathrm{CD}$ with a CDAI score $\geq 220$ and previously unsuccessful treatment with corticosteroids and immunomodulatory agents were randomized to receive either a low $\left(2 \times 10^{6} \mathrm{BM}-\mathrm{MSCs} / \mathrm{kg}\right)$ or a high $\left(8 \times 10^{6}\right.$ BM-MSCs $/ \mathrm{kg}$ ) dose of MSCs by intravenous infusion. After 28 days all patients had a decrease in their CDAI score, with a mean decrease of $105(P=0.004)$, and three patients had a clinical response (reduction in $\mathrm{CDAI} \geq 100$ ), one of whom entered clinical remission (CDAI <150). Patients reported an increased quality of life, as attested by a significant increase in mean Inflammatory Bowel Disease Questionnaire (IBDQ) score by day $28(P=0.008)$. No infusion reaction was observed, although five patients experienced mild to moderate adverse events [232].

The Nanjing group, who studied the use of MSCs in the autoimmune disease SLE, reported their experience of allogeneic MSC transplantation in seven patients with IBD, among whom four had CD and three had UC. They administered one intravenous infusion of BM-MSCs from healthy family members or UCMSCs at a dose of $1 \times 10^{6} / \mathrm{kg}$ body weight. Patients continued their treatment with corticosteroids and/or immunosuppressive agents after the transplant. After 3 months they observed a significant reduction in disease activity (CDAI or Clinical Activity Index) in all patients, with remission achieved in five out of seven patients (two out of four with CD and three out of three with UC) and endoscopic improvement with a decrease in Endoscopic Index of Severity score or in Endoscopic Activity Index in three out of seven patients, two out of four with CD and one out of three with UC. Remission lasted for more than 2 years in two patients, while two other patients relapsed at 6 and 
7 months. One CD patient had a significant reduction in fistula size and drainage. Histological analysis of biopsy specimens showed a reduction in the extent of the inflamed area and in the lymphocytic infiltration in the mucosa propria. One patient had a significant reduction in fistula size and drainage. No serious adverse events were reported after a mean follow-up of 19 months (range 6-32 months) [233].

\subsection{The future of mesenchymal stromal cell treatment in inflammatory bowel diseases}

\subsubsection{Ongoing protocols}

\subsubsection{Mesenchymal stromal cell treatment for fistulizing Crohn's disease}

\subsection{The Navarra study (NCT01157650)}

This phase I-II study is evaluating viability, safety, and tolerance of locally implanted autologous ASCs in 15 patients with nonactive CD (CDAI $\leq 200)$ and one or more enterocutaneous, rectovaginal or complex perianal fistulas. Patients should not have perianal abscesses or rectal and/or anal stenosis, and should not have received anti-TNF therapy or have received tacrolimus or cyclosporine within 8 weeks and 4 weeks before MSC therapy respectively. Secondary outcomes include an evaluation of efficacy (fistula healing, quality of life, presence of systemic CD, relapse) and a biological characterization of the MSCs used in terms of their phenotype, immune suppressive capacities, and cytokine production. This study is ongoing, but is no longer recruiting participants (Figure 50.8).

\subsection{The Leiden study (NCT01144962)}

This dose-escalation phase I-II study aims to determine the safety and efficacy of intrafistular injection of allogeneic
BM-MSCs for the induction of response of active fistulizing CD. The fistulas are peri-anal fistulas refractory to conventional medical treatment. Patients are randomized into one of four groups, receiving either placebo or MSCs at doses of 10 million, 30 million, or 90 million. Exclusion criteria include acute perianal infection, rectovaginal or complex peri-anal fistulas with more than two internal openings, and anti-TNF therapy less than 8 weeks prior to enrolment. Secondary outcomes at 12 weeks are improvement of clinical and endoscopic scores, quality of life details, and serum CRP. Safety is evaluated after 12 and 24 weeks. This study is ongoing, but is no longer recruiting participants.

\subsection{The Anterogen studies (NCT01314092, NCT01623453)}

In a phase II trial, patients with complex perianal fistulas are randomized to receive autologous ASCs at either low $\left(1 \times 10^{9} /\right.$ $\mathrm{mL})$ or high $\left(2 \times 10^{9} / \mathrm{mL}\right)$ dose, followed by a second double-dose injection if complete closure is not achieved. Primary outcome is complete closure of the fistula at week 8 . Safety is assessed by the reporting of all adverse events. Subsequently, an open follow-up clinical trial will evaluate the number of patients with sustained complete closure and the number of adverse events 6 months after the final dose injection.

\subsection{The TiGenix study (NCT01541579)}

This phase III randomized double-blind placebo-controlled multicenter study is evaluating the efficacy of allogeneic ASCs for the treatment of complex anal fistulas in patients with CD. Patients with nonactive or mildly active luminal CD (CDAI $\leq 220$ ) and two or less complex perianal fistulas are randomized to receive either an intrafistular injection of $120 \times 10^{6}$ allogeneic ASCs or placebo. Patients with abscesses, rectovaginal fistulas, surgically treated fistulas, and ongoing corticosteroid treatment or corticosteroid within the preceding 4 weeks are excluded from

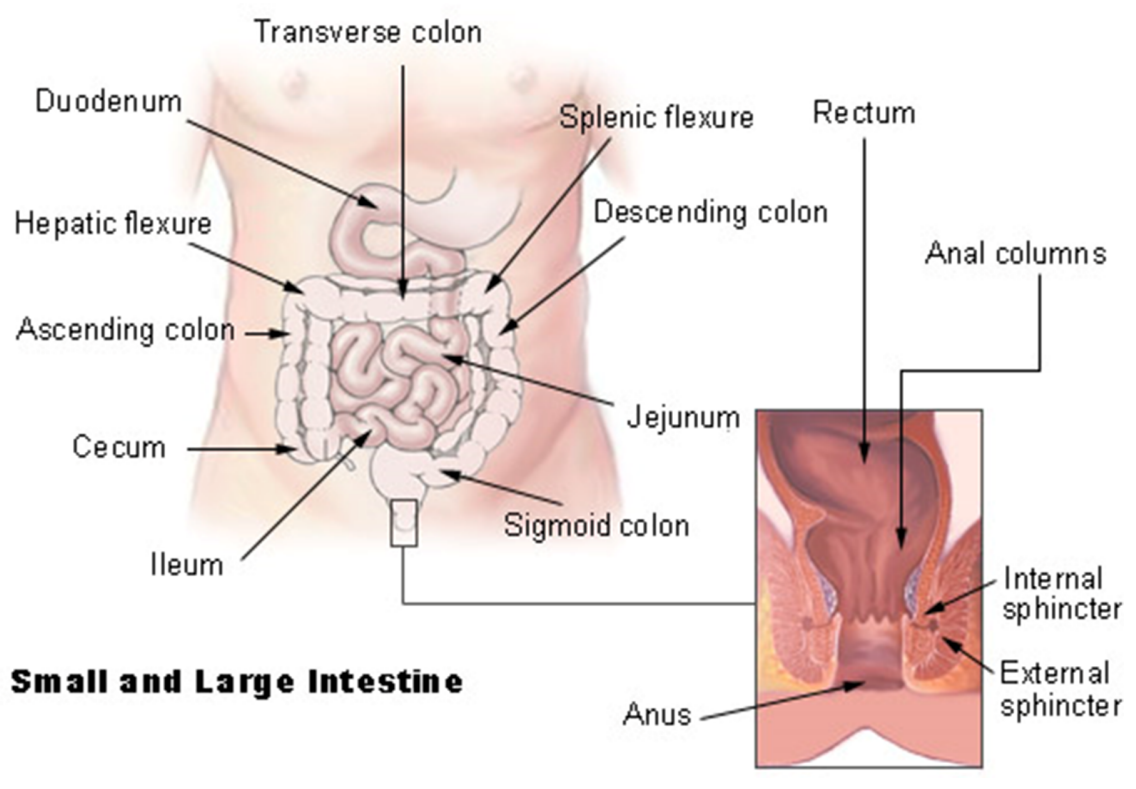

Figure 50.8 The small and large intestine with an insert of the perianal anatomy, an area where perianal fistulas occur in persons with CD. Source: http://commons.wikimedia.org/wiki/ File:Illu_intestine.jpg\#mediaviewer/File: Illu_intestine.jpg. 
the study. Primary outcomes include remission of perianal fistulizing CD at week 24 by clinical and MRI assessment. Other outcomes are efficacy, including response, time to response, and time to remission, and assessment using the PDAI and IBDQ criteria, as well as safety at weeks 24 and 52 . This study is currently recruiting participants.

\subsection{The Royan study (NCT01874015)}

This study is a prospective, randomized, phase I trial in which patients with refractory $\mathrm{CD}$, a CDAI score $>220$, and perineal fistulas are randomized to receive four monthly intrafistular injections of autologous BM-MSCs with or without fibroblasts. Outcomes are fistula closure and CDAI score at month 4 . This study is currently recruiting participants.

\subsubsection{Mesenchymal stromal cell administration for luminal inflammatory bowel diseases}

\subsection{The Liège study (NCT01540292)}

This prospective open-label phase I-II pilot trial was initiated in 2013 to explore the safety and efficacy of allogeneic BM-MSC infusions in CD refractory or intolerant to conventional therapies. Twenty patients with active refractory $\mathrm{CD}$ defined by a CDAI >220 despite conventional treatment, including mesalazine, corticosteroids, purine analogues, methotrexate, infliximab, and adalimumab, are treated with two successive injections of $1.5-2.0 \times 10^{6}$ allogeneic BM-MSCs/kg at the beginning of the trial and 4 weeks later. Conventional treatments of $\mathrm{CD}$, such as mesalazine, methylprednisolone, budesonide, azathioprine, 6mercaptopurine, or methotrexate, are allowed, while anti-TNF antibodies are forbidden, and antibiotics are allowed only for the treatment of a concurrent infection. The primary endpoint is a clinical response defined by a 100-point decrease in the CDAI score at week 8 . Secondary endpoints include clinical response, remission defined by a CDAI score $<150$, CDAI levels, CRP levels, and fecal calprotectin levels at weeks 2, 4, 8, and 12 . Immune modulation is being investigated by monitoring of nucleated cell counts, leucocyte subpopulations, Treg numbers, immunoglobulin levels, $\mathrm{V} \beta$ repertoire of T lymphocytes, and the quantification of TRECS in T lymphocytes. TRECS are TCR excision circles, which are small circles of DNA created in T cells during their passage through the thymus as they rearrange their TCR genes. This is a measure of thymic function. Safety is being assessed by recording side effects, including infections.

\subsection{The Mesoblast international studies (NCT01233960 and NCT00543374)}

In a first phase III study, patients with moderate-to-severe CD (CDAI scores between 250 and 450) who are intolerant to, or who have previously failed, therapy with at least one corticosteroid course and at least one immunosuppressive agent course and an anti-TNF treatment are randomized into three groups to receive a placebo or an intravenous injection of allogeneic MSCs at low $\left(6 \times 10^{6} \mathrm{MSCs}\right)$ or high $\left(1.2 \times 10^{9}\right)$ doses on four occasions over 2 weeks. The primary outcome is disease remission (CDAI score $\leq 150$ ) at day 28 , and secondary outcomes are disease improvement (reduction in CDAI score of $\geq 100$ points), improvement in quality of life (using the IBDQ), and reduction in number of draining fistulas. In a second phase III study, patients who successfully achieved clinical benefit in the first study will be enrolled and followed for duration and reinduction of clinical benefit using the CDAI questionnaire and improvement in quality of life using the IBDQ after 6 months.

\subsection{The Qingdao study (NCT01221428)}

This phase I-II study aims to determine the safety and efficacy of UCMSCs in refractory UC. First, $2 \times 10^{7}$ MSCs are injected intravenously followed 1 week later by $1 \times 10^{7}$ MSCs injected into the mesenteric artery. Outcomes evaluated after 3 months are improvement in endoscopy findings and histology and amelioration of clinical symptoms.

\subsection{The La Paz study (NCT01914887)}

In this phase I-II study, patients with left-sided colitis and moderate activity as assessed using a modified Truelove-Witts score between 11 and 21, who did not respond to 4 weeks of treatment with oral and/or topical 5-aminosalicylates, receive multiple endoscopic injections of allogeneic ASCs into the affected colonic submucosa at a total dose of $6 \times 10^{7}$ MSCs. Safety and efficacy assessed by the modified Truelove-Witts score, IBDQ, Mayo endoscopic index, CRP, and fecal calprotectin are evaluated at weeks $0,4,8$, and 12 . The study is currently recruiting.

\subsection{The Washington study (NCT02150551)}

In this phase I trial, pediatric patients with IBDs will be randomized into three dose groups and will receive eight weekly infusions of allogeneic BM-MSCs. Safety and efficacy will be assessed using the pediatric CDAI or Pediatric Ulcerative Colitis Activity Index questionnaires, quality of life using the Impact III IBD questionnaire, laboratory tests, including CRP, fecal calprotectin, and proinflammatory cytokines, as well as endoscopic healing evaluated at day 24 and day 77.

\subsection{Issues to be resolved}

\subsubsection{Source of mesenchymal stromal cells}

Most of the published human trials in people with CD have used ASCs. Only Ciccocioppo et al. used BM-MSCs [229]. ASCs have the advantage of being easily accessible in large numbers. MSC treatment requires a large number of cells, and, although MSCs have great proliferation potential, extended ex vivo expansion can alter their properties, resulting in reduced differentiation potential and senescence from the sixth passage onward [234].

Alternatively, expanded ASCs could be superior to nonexpanded ASCs, known as the stromal vascular fraction, for the treatment of enterocutaneous fistula in CD, as shown by GarcíaOlmo et al. in eight patients: three of four fistulas healed in the ASC group compared to one of four in the stromal vascular 
fraction group [235]. We lack information on differences on immunophenotype, differentiation potential, transcriptome, and proteome between BM-MSCs and ASCs. In vitro studies suggest that ASCs might be superior to BM-MSCs in suppressing immune responses [236,237]. In practice, both types of cells have demonstrated some efficacy, but formal studies comparing the efficacy of BM-MSCs and ASCs will be needed to resolve this question.

\subsubsection{Autologous versus allogeneic mesenchymal stromal cells}

The use of autologous MSCs has raised a debate on whether MSCs are affected by, or may contribute to, CD. MSCs from patients with other autoimmune diseases, such as SLE, have lower proliferation capacities [238], and the results in human studies on SLE were disappointing when autologous MSCs were used. However, several in vitro studies have demonstrated that MSCs from patients with $\mathrm{CD}$ have similar growth potential and $\mathrm{T}$ cell suppression properties to MSCs from healthy donors $[231,239]$. Moreover, both autologous and allogeneic MSCs seem promising in human trials, with the exception of a trial using autologous MSCs in SLE.

\subsubsection{Dosage and modalities of administration}

Because of the extent and dissemination of luminal lesions in CD, systemic administration seems required. In mice, intravenous and intraperitoneal routes of administration have been used with equal success, apart from a few studies in which MSCs did not appear to home to inflamed intestine [196,218]. In humans, intravenous infusion of cells is simple, minimally invasive, routinely performed, and safe. However, little is known about the optimal amount of MSCs and the proportion of MSCs that will reach an inflamed intestine. Duijvestein et al. used 1-2 $\times 10^{6}$ autologous MSCs/kg body without much success [231], while Onken et al. observed no significant difference between low $\left(2 \times 10^{6} \mathrm{MSCs} / \mathrm{kg}\right)$ and high $\left(8 \times 10^{6} \mathrm{MSCs} / \mathrm{kg}\right)$ [232]. Administration of MSCs via selective mesenteric artery cannulation has been successfully performed in one patient, without any complication [240]. This route of administration may increase the number of MSCs reaching the inflamed organ, but its superiority over the intravenous administration is yet to be demonstrated.

Local injection of MSCs has been successfully used in several studies to treat $\mathrm{CD}$ fistulas. In studies showing efficacy of intrafistular injections, $10-60 \times 10^{6}$ MSCs were injected into each fistulous tract, and these injections were sometimes repeated. Ongoing trials are testing higher systemic doses: the Mesoblast international studies are testing the injection of $6 \times 10^{8}$ or $1.2 \times 10^{9}$ cells four times over a 2 -week period. Several local dose-escalation trials are also currently ongoing.

\subsubsection{Concomitant use of other drugs}

MSCs are used concomitantly with immunosuppressive drugs, and, as they have common targets, it is important to know if the drugs can affect MSC function. MSCs exposed to physiological concentrations of azathioprine, methotrexate, 6-mercaptopurine, and anti-TNF- $\alpha$ antibodies had normal survival and inhibitory capacities on PBMC proliferation when tested in vitro. An additive effect could even exist with 6-mercaptopurine and anti-TNF- $\alpha$ antibodies [241].

\subsection{Safety}

So far there have been no reports of any serious adverse events or ectopic tissue growth in clinical trials using MSC-based therapy for CD, nor for graft-versus-host disease [242-244], solid-organ transplantation [245], cartilage disorders [246], or in many completed clinical trials for a variety of applications [247,248]. In some studies there was a mild and transient fever shortly after the time of administration, and this association was found to be statistically significant in a meta-analysis [248]. More experience is needed in order to confirm the long-term safety of MSCs.

The immunosuppressive properties of MSCs could theoretically increase susceptibility to infections and cancers. However, no infections or malignant diseases have been reported as serious adverse events in MSC-treated CD patients, and there is no evidence of any increased risk in other applications [248]. In the context of solid organ transplantation with MSC-based immunosuppression, one group has even observed a decreased infection risk compared with standard immunosuppressive drugs [245]. Another reason for concern for an increased risk of malignant disease is the need to expand MSCs in vitro in order to obtain a sufficient number of cells for MSC-based therapy. While murine MSCs have shown a potential for the development of chromosomal aberrations and tumor generation after longterm in vitro culture [249,250], human MSCs have not shown any of these risks so far [251-253]. Moreover, IBDs are associated with a higher risk of developing colorectal cancer. In a murine model of colitis-associated tumorigenesis induced by azoxymethane and DSS, MSC-treated animals showed a significant reduction in tumor number and tumor load compared with control mice, while tumor size remained comparable. This could be linked to a decreased expression of proinflammatory cytokines and downregulation of STAT3 phosphorylation [254].

Finally, the effects of MSCs on preexisting cancers have also been studied. In animal studies some authors found that MSCs could promote tumor growth $[255,256]$, while others observed a tumor-suppressive activity of MSCs [257-259]. This dual effect could be explained by a context-dependent role of MSCs in regulating tumor growth $[260,261]$. In a small human trial of 25 patients, co-transplantation of MSCs and HSCs was associated with a higher relapse rate compared with control patients (60\% versus $20 \%$ ). However, this observation has not been confirmed by other studies [262].

\subsection{Conclusions}

MSCs represent a promising therapy for IBD, especially for $\mathrm{CD}$. They probably exert their effects through a combination of 
immunomodulation, myogenic differentiation, and the promotion of epithelial repair. Both local injection of MSCs for fistulizing CD and intravenous injection of MSCs for luminal IBD have shown interesting results in several human trials. Unlike current surgical strategies, MSC administration is a minimally invasive procedure, which does not injure the anal sphincter and even promotes a nonfibrotic reparative process of fistulas, with no cases of incontinence reported after MSC treatment. MSCs seem superior to conventional drugs in term of side effects, such as opportunist infections. There are still many questions to answer concerning the optimal source of MSCs, as well as dosage and routes of administration.

The efficacy of MSCs compared with conventional treatments still needs to be demonstrated in randomized controlled trials, several studies of which are ongoing. They will also likely help us in the understanding and use of MSCs to treat IBDs.

\section{References}

1 E. V. Loftus Jr. Clinical epidemiology of inflammatory bowel disease: incidence, prevalence, and environmental influences. Gastroenterology 2004;126:1504-1517.

2 A. Dignass, R. Eliakim, F. Magro, et al. Second European evidencebased consensus on the diagnosis and management of ulcerative colitis part 1: definitions and diagnosis. J Crohns Colitis 2012;6:965-990.

3 C. G. Su, T. A. Judge, G. R. Lichtenstein. Extraintestinal manifestations of inflammatory bowel disease. Gastroenterol Clin North Am 2002;31:307-327.

4 G. Van Assche, A. Dignass, J. Panes, et al. The second European evidence-based consensus on the diagnosis and management of Crohn's disease: definitions and diagnosis. J Crohns Colitis 2010;4:7-27.

5 A. Franke, D.P. McGovern, J. C. Barrett, et al. Genome-wide metaanalysis increases to 71 the number of confirmed Crohn's disease susceptibility loci. Nat Genet 2010;42:1118-1125.

6 J. Cosnes, C. Gower-Rousseau, P. Seksik, A. Cortot. Epidemiology and natural history of inflammatory bowel diseases. Gastroenterology 2011;140:1785-1794.

7 B. Chassaing, A. Darfeuille-Michaud. The commensal microbiota and enteropathogens in the pathogenesis of inflammatory bowel diseases. Gastroenterology 2011;140:1720-1728.

8 T. T. MacDonald, I. Monteleone, M.C. Fantini, G. Monteleone. Regulation of homeostasis and inflammation in the intestine. Gastroenterology 2011;140:1768-1775.

9 K. Ina, J. Itoh, K. Fukushima, et al. Resistance of Crohn's disease T cells to multiple apoptotic signals is associated with a Bcl-2/Bax mucosal imbalance. J Immunol 1999;163:1081-1090.

10 J. Itoh, C. de La Motte, S. A. Strong, et al. Decreased Bax expression by mucosal $\mathrm{T}$ cells favours resistance to apoptosis in Crohn's disease. Gut 2001;49:35-41.

11 W. Strober, I. J. Fuss. Proinflammatory cytokines in the pathogenesis of inflammatory bowel diseases. Gastroenterology 2011;140:1756-1767.

12 S. I. Siakavellas, G. Bamias. Role of the IL-23/IL-17 axis in Crohn's disease. Discov Med 2012;14:253-262.
13 S. Bandzar, S. Gupta, M. O. Platt. Crohn's disease: a review of treatment options and current research. Cell Immunol 2013;286:45-52.

14 M. F. Neurath, I. Fuss, B. L. Kelsall, et al. Antibodies to interleukin 12 abrogate established experimental colitis in mice. J Exp Med 1995; 182:1281-1290.

15 Z. Liu, K. Beboes, H. Heremans, et al. Role of interleukin-12 in the induction of mucosal inflammation and abrogation of regulatory $\mathrm{T}$ cell function in chronic experimental colitis. Eur J Immunol 2001;31:1550-1560.

16 I.J. Fuss, C. Becker, Z. Yang, et al. Both IL-12p70 and IL-23 are synthesized during active Crohn's disease and are down-regulated by treatment with anti-IL-12 p40 monoclonal antibody. Inflamm Bowel Dis 2006;12:9-15.

17 A. L. Hart, H. O. Al-Hassi, R. J. Rigby, et al. Characteristics of intestinal dendritic cells in inflammatory bowel diseases. Gastroenterology 2005;129:50-65.

18 K. Matsuaka, N. Inoue, T. Sato, et al. T-bet upregulation and subsequent interleukin 12 stimulation are essential for induction of Th1 mediated Immunopathology in Crohn's disease. Gut 2004;53:1303-1308.

19 B. Oppman, R. Lesley, B. Blom, et al. Novel p19 protein engages IL$12 \mathrm{p} 40$ to form a cytokine, IL-23, with biological activities similar as well as distinct from IL-12. Immunity 2000;13:715-725.

20 S. Aggarwal, N. Ghilardi, M. H. Xie, et al. Interleukin-23 promotes a distinct CD4 T cell activation state characterized by the production of interleukin-17. J Biol Chem 2003;278:1910-1914.

21 D. Yen, J. Cheung, H. Scheerens, et al. IL-23 is essential for T cellmediated colitis and promotes inflammation via IL-17 and IL-6. J Clin Invest 2006;116:1310-1316.

22 Y. Chen, C. L. Langrish, B. McKenzie, et al. Anti-IL-23 therapy inhibits multiple inflammatory pathways and ameliorates autoimmune encephalomyelitis. J Clin Invest 2006;116:1317-1326.

23 S. Hue, P. Ahern, S. Buonocore, et al. Interleukin-23 drives innate and $\mathrm{T}$ cell-mediated intestinal inflammation. $J$ Exp Med 2006;203:2473-2483.

24 M. C. Kullberg, D. Jankovic, C. G. Feng, et al. IL-23 plays a key role in Helicobacter hepaticus-induced T cell-dependent colitis. J Exp Med 2006;203:2485-2494.

25 T. ten Hove, C. van Montfrans, M. P. Peppelenbosch, A. J. van Deventer. Infliximab treatment induces apoptosis of lamina propria T lymphocytes in Crohn's disease. Gut 2002;50:206-211.

26 J. M. Van den Brande, H. Braat, G. R. van den Brink, et al. Infliximab but not etanercept induces apoptosis in lamina propria T-lymphocytes from patients with Crohn's disease. Gastroenterology 2003; 124:1774-1785.

27 W. J. Sandborn, S. B. Hanauer, S. Katz, et al. Etanercept for active Crohn's disease: a randomized, double-blind, placebo-controlled trial. Gastroenterology 2001;121:1088-1094.

28 A. Nesbitt, G. Fossati, M. Bergin, et al. Mechanism of action of certolizumab pegol (CDP870): in vitro comparison with other antitumor necrosis factor alpha agents. Inflamm Bowel Dis 2007;13:1323-1332.

29 S. Schreiber, M. Khaliq-Kareemi, I. C. Lawrance, et al. Maintenance therapy with certolizumab pegol for Crohn's disease. N Engl J Med 2007;357:239-250.

30 S. Schreiber, P. Rutgeerts, R. N. Fedorak, et al. A randomized, placebo-controlled trial of certolizumab pegol (CDP870) for treatment of Crohn's disease. Gastroenterology 2005;129:807-818. 
31 J. Luna, M. C. Masamunt, I. C. Lawrance, M. Sans. Mesenchymal cell proliferation and programmed cell death: key players in fibrogenesis and new targets for therapeutic intervention. Am J Physiol Gastrointest Liver Physiol 2011;300:G703-G708.

32 W. R. Best, J. M. Becktel, J. W. Singleton, F. Kern Jr. Development of a Crohn's disease activity index. National Cooperative Crohn's Disease Study. Gastroenterology 1976;70 (3):439-444.

33 G. R. Lichtenstein, S. B. Hanauer, W. J. Sandborn, et al. Management of Crohn's disease in adults. Am J Gastroenterol 2009;104: 465-483.

34 W. J. Sandborn, B. G. Feagan, S. B. Hanauer, et al. A review of activity indices and efficacy endpoints for clinical trials of medical therapy in adults with Crohn's disease. Gastroenterology 2002;122: 512-530.

35 M. Daperno, G. D’Haens, G. Van Assche, et al. Development and validation of a new, simplified endoscopic activity score for Crohn's disease: the SES-CD. Gastrointest Endosc 2004;60:505-512.

36 A. Dignass, G. Van Assche, J. O. Lindsay, et al. The second European evidence-based consensus on the diagnosis and management of Crohn's disease: Current management. J Crohns Colitis 2010;4:28-62.

37 D. G. Binion, G. A. West, K. Ina, et al. Enhanced leukocyte binding by intestinal microvascular endothelial cells in inflammatory bowel disease. Gastroenterology 1997;112:1895-1907.

38 W. J. Sandborn, J. F. Colombel, R. Enns, et al. Natalizumab induction and maintenance therapy for Crohn's disease. $N$ Engl J Med 2005;353:1912-1925.

39 S. R. Targan, B. G. Feagan, R. N. Fedorak, et al. Natalizumab for the treatment of active Crohn's disease: results of the ENCORE trial. Gastroenterology 2007;132:1672-1683.

40 A. C. Ford, W. J. Sandborn, K. J. Khan, et al. Efficacy of biological therapies in inflammatory bowel disease: systematic review and meta-analysis. Am J Gastroenterol 2011;106:644-659.

41 W. J. Sandborn, B. G. Feagan, P. Rutgeerts, et al. Vedolizumab as induction and maintenance therapy for Crohn's disease. $N$ Engl J Med 2013;369:711-721.

42 S. Keshav, D. Johnson, T. Schall, P. Bekker. Chemokine receptor antagonist CCX282-B (Traficet- $\mathrm{En}^{\mathrm{TM}}$ ) maintained remission of Crohn's disease in PROTECT-1 study. Gastroenterology 2010; 138:S86.

43 D. W. Hommes, S. R. Targan, A. Dignass, et al. Visilizumab therapy in subjects with moderate-to-severe, refractory Crohn's disease. Gastroenterology 2007;132:A157.

44 D. C. Baumgart, J. N. Lowder, S. R. Targan, et al. Transient cytokine-induced liver injury following administration of the humanized anti-CD3 antibody visilizumab (HuM291) in Crohn's disease. Am J Gastroenterol 2009;104:868-876.

45 S. B. Hanauer, W. J. Sandborn, B. E. Sands, et al. A randomized placebo-controlled trial of abatacept for moderately-toseverely active Crohn's disease (CD). Gastroenterology 2010; 138:S86.

46 W. Strober, F. Zhang, A. Kitani, et al. Proinflammatory cytokines underlying the inflammation of Crohn's disease. Curr Opin Gastroenterol 2010;26:310-317.

47 W. J. Sandborn, C. Gasink, L. L. Gao, et al. Ustekinumab induction and maintenance therapy in refractory Crohn's disease. $N$ Engl J Med 2012;367:1519-1528.
48 M. Yamamoto, K. Yoshizaki, T. Kishimoto, H. Ito. IL-6 is required for the development of Th1 cell-mediated murine colitis. JImmunol 2000;164:4878-4882.

49 R. Atreya, J. Mudter, S. Finotto, et al. Blockade of interleukin 6 trans signaling suppresses $\mathrm{T}$ cell resistance against apoptosis in chronic intestinal inflammation: evidence in Crohn disease and experimental colitis in vivo. Nat Med 2000;6:583-588.

50 H. Ito, M. Takazoe, Y. Fukuda, et al. A pilot randomized trial of a human anti-interleukin- 6 receptor monoclonal antibody in active Crohn's disease. Gastroenterology 2004;126:989-996.

51 M. Lazzerini, S. Martelossi, G. Magazzù, et al. Effect of thalidomide on clinical remission in children and adolescents with refractory Crohn disease: a randomized clinical trial. JAMA 2013;310: 2164-2173.

52 W. Hueber, B. E. Sands, S. Lewitzky, et al. Secukinumab, a human anti-IL-17A monoclonal antibody, for moderate to severe Crohn's disease: unexpected results of a randomised, double-blind placebocontrolled trial. Gut 2012;61:1693-1700.

53 S. R. Targan, B. G. Feagan, S. Vermeire, et al. A randomized, doubleblind, placebo-controlled study to evaluate the safety, tolerability, and efficacy of AMG 827 in subjects with moderate to severe Crohn's disease. Gastroenterology 2012;143;E26.

54 W. Reinisch, W. de Villiers, L. Bene, et al. Fontolizumab in moderate to severe Crohn's disease: a phase 2, randomized, double-blind, placebo-controlled, multiple-dose study. Inflamm Bowel Dis 2010;16:233-242.

55 S. Schreiber, R. N. Fedorak, O. H. Nielsan, et al. Safety and efficacy of recombinant human interleukin 10 in chronic active Crohn's disease. Gastroenterology 2000;119:1461-1472.

56 F. E. Buruiana, I. Solà, P. Alonso-Coello. Recombinant human interleukin 10 for induction of remission in Crohn's disease. Cochrane Database Syst Rev 2010;(11):CD005109.

57 B. E. Sands, S. Bank, C. A. Sninsky, et al. Preliminary evaluation of safety and activity of recombinant human interleukin 11 in patients with active Crohn's disease. Gastroenterology 1999;117:58-64.

58 K. R. Herrlinger, T. Witthoeft, A. Raedler, et al. Randomized, double blind controlled trial of subcutaneous recombinant human interleukin-11 versus prednisolone in active Crohn's disease. Am J Gastroenterol 2006;101:793-797.

59 A. E. Slonim, L. Bulone, M. B. Damore, et al. A preliminary study of growth hormone therapy for Crohn's disease. $N$ Engl J Med 2000;342:1633-1637.

60 J. Bassaganya-Riera, R. Hontecillas, W. Horne, et al. Conjugated linoleic acid modulates immune responses in patients with mild to moderately active Crohn's disease. Clin Nutr 2012;31:721-727.

61 J. P. Smith, S. I. Bingaman, F. Ruggiero, et al. Therapy with the opioid antagonist naltrexone promotes mucosal healing in active Crohn's disease: a randomized placebo-controlled trial. Dig Dis Sci 2011;56:2088-2097.

62 R. W. Summers, D. E. Elliott, J. F. Urban Jr, et al. Trichuris suis therapy in Crohn's disease. Gut 2005;54:87-90.

63 J. Croese, J. O'Neil, J. Masson, et al. A proof of concept study establishing Necator americanus in Crohn's patients and reservoir donors. Gut 2006;55:136-137.

64 M. T. Abreu, C. Von Tirpitz, P. J. Mannon, et al. Extracorporeal photoimmune therapy for refractory moderately active Crohn's disease: a multicenter, open-label study. Gastroenterology 2007;132:A157. 
65 J. R. Korzenik, B. K. Dieckgraefe, J. F. Valentine, et al. Sargramostim for active Crohn's disease. N Engl J Med 2005;352:2193-2201.

66 L. Roth, J. K. Macdonald, J. W. McDonald, N. Chande. Sargramostim (GM-CSF) for induction of remission in Crohn's disease. Cochrane Database Syst Rev 2011;(11):CD008538.

67 A. D. Butterworth, A. G. Thomas, A.K. Akobeng. Probiotics for induction of remission in Crohn's disease. Cochrane Database Syst Rev 2008;(3):CD006634.

68 V.E. Rolfe, P. J. Fortun, C. J. Hawkey, F. Bath-Hextall. Probiotics for maintenance of remission in Crohn's disease. Cochrane Database Syst Rev 2006;(4):CD004826.

69 K. Whelan, E. M. Quigley. Probiotics in the management of irritable bowel syndrome and inflammatory bowel disease. Curr Opin Gastroenterol 2013;29:184-189.

70 A. Bourreille, G. Cadiot, G. Le Dreau, et al. Saccharomyces boulardii does not prevent relapse of Crohn's disease. Clin Gastroenterol Hepatol 2013;11:982-987.

71 J. L. Benjamin, C. R. Hedin, A. Koutsoumpas, et al. Randomised, double-blind, placebo-controlled trial of fructo-oligosaccharides in active Crohn's disease. Gut 2011;60:923-929.

72 E. Harrison, P. Allan, A. Ramu, et al. Management of intestinal failure in inflammatory bowel disease: small intestinal transplantation or home parenteral nutrition? World J Gastroenterol 2014;20:3153-3163.

73 N. Sustento-Reodica, P. Ruiz, A. Rogers, et al. Recurrent Crohn's disease in transplanted bowel. Lancet 1997;349:688-691.

74 B. Kaila, D. Grant, N. Pettigrew, et al. Crohn's disease recurrence in a small bowel transplant. Am J Gastroenterol 2004;99:158-162.

75 K. M. Abu-Elmagd, B. Kosmach-Park, G. Costa, et al. Long-term survival, nutritional autonomy, and quality of life after intestinal and multivisceral transplantation. Ann Surg 2012;256:494-508.

76 P. E. Drakos, A. Nagler, R. Or. Case of Crohn's disease in bone marrow transplantation. Am J Hematol 1993;43:157-158.

77 O. García-Bosch, E. Ricart, J. Panés. Review article: stem cell therapies for inflammatory bowel disease - efficacy and safety. Aliment Pharmacol Ther 2010;32:939-952.

78 A. Gratwohl, J. Passweg, C. Bocelli-Tyndall, et al. Autologous hematopoietic stem cell transplantation for autoimmune diseases. Bone Marrow Transplant 2005;35:869-879.

79 R. K. Burt, R. M. Craig, F. Milanetti, et al. Autologous nonmyeloablative hematopoietic stem cell transplantation in patients with severe anti-TNF refractory Crohn disease: long-term follow-up. Blood 2010;116:6123-6132.

80 C.J. Hawkey. Stem cells as treatment in inflammatory bowel disease. Dig Dis 2012;30(Suppl 3):134-139.

81 A. Dignass, J. O. Lindsay, A. Sturm, et al. Second European evidence-based consensus on the diagnosis and management of ulcerative colitis part 2: current management. J Crohns Colitis 2012;6:991-1030.

82 B. G. Feagan, G. R. Greenberg, G. Wild, et al. Treatment of ulcerative colitis with a humanized antibody to the $\alpha_{4} \beta_{7}$ integrin. N Engl J Med 2005;352:2499-2507.

83 P. J. Rutgeerts, R. N. Fedorak, D. W. Hommes, et al. A randomised phase I study of etrolizumab (rhuMAb $\beta 7$ ) in moderate to severe ulcerative colitis. Gut 2013;62:1122-1130.

84 S. Vermeire, S. O'Byrne, M. Keir, et al. Etrolizumab as induction therapy for ulcerative colitis: a randomised, controlled, phase 2 trial. Lancet 2014;384:309-318.
85 S. Vermeire, S. Ghosh, J. Panes, et al. The mucosal addressin cell adhesion molecule antibody PF-00547,659 in ulcerative colitis: a randomised study. Gut 2011;60:1068-1075.

86 P. B. Miner Jr, R. S. Geary, J. Matson, et al. Bioavailability and therapeutic activity of alicaforsen (ISIS 2302) administered as a rectal retention enema to subjects with active ulcerative colitis. Aliment Pharmacol Ther 2006;23:1427-1434.

87 P. B. Miner Jr, M. K. Wedel, S. Xia, B. F. Baker. Safety and efficacy of two dose formulations of alicaforsen enema compared with mesalazine enema for treatment of mild to moderate left-sided ulcerative colitis: a randomized, double-blind, active-controlled trial. Aliment Pharmacol Ther 2006;23:1403-1413.

88 S. J. van Deventer, J. A. Tami, M. K. Wedel. A randomised, controlled, double blind, escalating dose study of alicaforsen enema in active ulcerative colitis. Gut 2004;53:1646-1651.

89 W. J. Sandborn, S. Ghosh, J. Panes, et al. Tofacitinib, an oral Janus kinase inhibitor, in active ulcerative colitis. $N$ Engl $J$ Med 2012;367:616-624.

90 R. A. Kozarek, D. J. Patterson, M. D. Gelfand, et al. Methotrexate induces clinical and histologic remission in patients with refractory inflammatory bowel disease. Ann Intern Med 1989;110:353-356.

91 T. H. Baron, C. D. Truss, C. O. Elson. Low-dose oral methotrexate in refractory inflammatory bowel disease. Dig Dis Sci 1993;38: $1851-1856$.

92 J. R. Cummings, K. R. Herrlinger, S. P. Travis, et al. Oral methotrexate in ulcerative colitis. Aliment Pharmacol Ther 2005;21:385-389.

93 M. Aloi, G. Di Nardo, F. Conte, et al. Methotrexate in paediatric ulcerative colitis: a retrospective survey at a single tertiary referral centre. Aliment Pharmacol Ther 2010;32:1017-1022.

94 S. Willot, A. Noble, C. Deslandres. Methotrexate in the treatment of inflammatory bowel disease: an 8 -year retrospective study in a Canadian pediatric IBD center. Inflamm Bowel Dis 2011;17: 2521-2516.

95 J. L. Anderson, R. J. Edney, K. Whelan. Systematic review: faecal microbiota transplantation in the management of inflammatory bowel disease. Aliment Pharmacol Ther 2012;36:503-516.

96 T. J. Borody, E. F. Warren, S. Leis, et al. Treatment of ulcerative colitis using fecal bacteriotherapy. J Clin Gastroenterol 2003;37: $42-47$.

97 G. Van Assche, I. Dalle, M. Noman, et al. A pilot study on the use of the humanized anti-interleukin-2 receptor antibody daclizumab in active ulcerative colitis. Am J Gastroenterol 2003;98: 369-376.

98 G. Van Assche, W. J. Sandborn, B. G. Feagan, et al. Daclizumab, a humanised monoclonal antibody to the interleukin 2 receptor (CD25), for the treatment of moderately to severely active ulcerative colitis: a randomised, double blind, placebo controlled, dose ranging trial. Gut 2006;55:1568-1574.

99 T. J. Creed, M. R. Norman, C. S. Probert, et al. Basiliximab (anti$\mathrm{CD} 25)$ in combination with steroids may be an effective new treatment for steroid-resistant ulcerative colitis. Aliment Pharmacol Ther 2003;18:65-75.

100 T. J. Creed, C. S. Probert, M. N. Norman, et al. Basiliximab for the treatment of steroid-resistant ulcerative colitis: further experience in moderate and severe disease. Aliment Pharmacol Ther 2006;23:1435-1442. 
101 B. E. Sands, W. J. Sandborn, T. J. Creed, et al. Basiliximab does not increase efficacy of corticosteroids in patients with steroid-refractory ulcerative colitis. Gastroenterology 2012;143:356-364.

102 S. Plevy, B. Salzberg, G. Van Assche, et al. A phase I study of visilizumab, a humanized anti-CD3 monoclonal antibody, in severe steroid-refractory ulcerative colitis. Gastroenterology 2007;133: 1414-1422.

103 M. Sparrow. Visilizumab in severe ulcerative colitis: good vision but blurry results. Inflamm Bowel Dis 2008;14:1022-1023.

104 W. J. Sandborn, J. F. Colombel, M. Frankel, et al. Anti-CD3 antibody visilizumab is not effective in patients with intravenous corticosteroid-refractory ulcerative colitis. Gut 2010;59:1485-1492.

105 K. Leiper, K. Martin, A. Ellis, et al. Randomised placebo-controlled trial of rituximab (anti-CD20) in active ulcerative colitis. Gut 2011;60:1520-1526.

106 D. El Fassi, C. H. Nielsen, J. Kjeldsen, et al. Ulcerative colitis following B lymphocyte depletion with rituximab in a patient with Graves' disease. Gut 2008;57:714-715.

107 M. Goetz, R. Atreya, M. Ghalibafian, et al. Exacerbation of ulcerative colitis after rituximab salvage therapy. Inflamm Bowel Dis 2007;13:1365-1368.

108 K. Le Blanc. Mesenchymal stromal cells: tissue repair and immune modulation. Cytotherapy 2006;8:559-561.

109 M. Dominici, K. Le Blanc, I. Mueller, et al. Minimal criteria for defining multipotent mesenchymal stromal cells. The International Society for Cellular Therapy position statement. Cytotherapy 2006;8:315-317.

110 J. W. Kim, S.Y. Kim, S. Y. Park, et al. Mesenchymal progenitor cells in the human umbilical cord. Ann Hematol 2004;83:733-738.

111 A. Erices, P. Conget, J. J. Minguell. Mesenchymal progenitor cells in human umbilical cord blood. Br J Haematol 2000;109: 235-242.

112 Y. Zhang, C. Li, X. Jiang, et al. Human placenta-derived mesenchymal progenitor cells support culture expansion of long-term culture-initiating cells from cord blood CD $34^{+}$cells. Exp Hematol 2004;32:657-664.

113 P. A. Zuk, M. Zhu, P. Ashjian, et al. Human adipose tissue is a source of multipotent stem cells. Mol Biol Cell 2002;13:4279-4295.

114 Q. Zhang, S. Shi, Y. Liu, et al. Mesenchymal stem cells derived from human gingiva are capable of immunomodulatory functions and ameliorate inflammation-related tissue destruction in experimental colitis. J Immunol 2009;183:7787-7798.

115 J. G. Toma, M. Akhavan, K. J. Fernandes, et al. Isolation of multipotent adult stem cells from the dermis of mammalian skin. Nat Cell Biol 2001;3:778-784.

116 C. G. Fan, F. W. Tang, Q. J. Zhang, et al. Characterization and neural differentiation of fetal lung mesenchymal stem cells. Cell Transplant 2005;14:311-321.

117 C. Campagnoli, I. A. Roberts, S. Kumar, et al. Identification of mesenchymal stem/progenitor cells in human first-trimester fetal blood, liver, and bone marrow. Blood 2001;98: 2396-2402.

118 M. J. Hoogduijn, M. J. Crop, A. M. Peeters, et al. Human heart, spleen, and perirenal fat-derived mesenchymal stem cells have immunomodulatory capacities. Stem Cells Dev 2007;16:597-604.

119 H. E. Young, M. L. Mancini, R. P. Wright, et al. Mesenchymal stem cells reside within the connective tissues of many organs. Dev Dyn 1995;202:137-144.
120 P. Alex, N. C. Zachos, T. Nguyen, et al. Distinct cytokine patterns identified from multiplex profiles of murine DSS and TNBSinduced colitis. Inflamm Bowel Dis 2009;15:341-352.

121 K. Le Blanc, L. Tammik, B. Sundberg, et al. Mesenchymal stem cells inhibit and stimulate mixed lymphocyte cultures and mitogenic responses independently of the major histocompatibility complex. Scand J Immunol 2003;57:11-20.

122 A. Bartholomew, C. Sturgeon, M. Siatskas, et al. Mesenchymal stem cells suppress lymphocyte proliferation in vitro and prolong skin graft survival in vivo. Exp Hematol 2002;30:42-48.

123 M. Di Nicola, C. Carlo-Stella, M. Magni, et al. Human bone marrow stromal cells suppress T-lymphocyte proliferation induced by cellular or nonspecific mitogenic stimuli. Blood 2002;99: 3838-3843.

124 M. Krampera, S. Glennie, J. Dyson, et al. Bone marrow mesenchymal stem cells inhibit the response of naive and memory antigenspecific T cells to their cognate peptide. Blood 2003;101:3722-3729.

125 I. Prigione, F. Benvenuto, P. Bocca, et al. Reciprocal interactions between human mesenchymal stem cells and $\gamma \delta$ T cells or invariant natural killer T cells. Stem Cells 2009;27:693-702.

126 S. Glennie, I. Soeiro, P. J. Dyson, et al. Bone marrow mesenchymal stem cells induce division arrest anergy of activated T cells. Blood 2005; 105:2821-2827.

127 F. Benvenuto, S. Ferrari, E. Gerdoni, et al. Human mesenchymal stem cells promote survival of T cells in a quiescent state. Stem Cells 2007;25:1753-1760.

128 K. Akiyama, C. Chen, D. Wang, et al. Mesenchymal-stem-cellinduced immunoregulation involves FAS-ligand-/FAS-mediated T cell apoptosis. Cell Stem Cell 2012;10:544-555.

129 I. Monteleone, G. Monteleone, D. Fina, et al. A functional role of flip in conferring resistance of Crohn's disease lamina propria lymphocytes to FAS-mediated apoptosis. Gastroenterology 2006;130: 389-397.

130 X. J. Liu, J. F. Zhang, B. Sun, et al. Reciprocal effect of mesenchymal stem cell on experimental autoimmune encephalomyelitis is mediated by transforming growth factor- $\beta$ and interleukin-6. Clin Exp Immunol 2009;158:37-44.

131 M. Di Ianni, B. Del Papa, M. De Ioanni, et al. Mesenchymal cells recruit and regulate $\mathrm{T}$ regulatory cells. Exp Hematol 2008;36: 309-318.

132 C. Prevosto, M. Zancolli, P. Canevali, et al. Generation of CD4 ${ }^{+}$or $\mathrm{CD}^{+}$regulatory $\mathrm{T}$ cells upon mesenchymal stem cell-lymphocyte interaction. Haematologica 2007;92:881-888.

133 Z. Ye, Y. Wang, H.Y. Xie, S. S. Zheng. Immunosuppressive effects of rat mesenchymal stem cells: involvement of $\mathrm{CD} 4{ }^{+} \mathrm{CD} 25^{+}$regulatory T cells. Hepatobiliary Pancreat Dis Int 2008;7:608-614.

134 E. Zappia, S. Casazza, E. Pedemonte et al. Mesenchymal stem cells ameliorate experimental autoimmune encephalomyelitis inducing T cell anergy. Blood 2005;106:1755-1761.

135 M. A. Gonzalez, E. Gonzalez-Rey, L. Rico, et al. Treatment of experimental arthritis by inducing immune tolerance with human adipose-derived mesenchymal stem cells. Arthritis Rheum 2009;60:1006-1019.

136 A. M. Madec, R. Mallone, G. Afonso, et al. Mesenchymal stem cells protect NOD mice from diabetes by inducing regulatory $\mathrm{T}$ cells. Diabetologia 2009;52:1391-1399.

137 K. English, J. M. Ryan, L. Tobin, et al. Cell contact, prostaglandin $\mathrm{E}_{2}$ and transforming growth factor beta 1 play non-redundant roles in 
human mesenchymal stem cell induction of $\mathrm{CD} 4^{+} \mathrm{CD} 25^{\text {High }}$ forkhead box $\mathrm{P}^{+}$regulatory $\mathrm{T}$ cells. Clin Exp Immunol 2009;156: 149-160.

138 S. A. Patel, J. R. Meyer, S. J. Greco, et al. Mesenchymal stem cells protect breast cancer cells through regulatory $\mathrm{T}$ cells: role of mesenchymal stem cell-derived TGF- $\beta$. J Immunol 2010;184:5885-5894.

139 K. Nemeth, A. Keane-Myers, J. M. Brown, et al. Bone marrow stromal cells use TGF- $\beta$ to suppress allergic responses in a mouse model of ragweed-induced asthma. Proc Natl Acad Sci U S A 2010;107:5652-5657.

140 Z. Selmani, A. Naji, I. Zidi, et al. Human leukocyte antigen-G5 secretion by human mesenchymal stem cells is required to suppress $\mathrm{T}$ lymphocyte and natural killer function and to induce $\mathrm{CD} 4{ }^{+} \mathrm{CD} 25^{\text {high }} \mathrm{FOXP}^{+}$regulatory $\mathrm{T}$ cells. Stem Cells 2008;26: 212-222.

141 N. Rouas-Freiss, A. Naji, A. Durrbach, E. D. Carosella. Tolerogenic functions of human leukocyte antigen G: from pregnancy to organ and cell transplantation. Transplantation 2007;84:S21-S25.

142 P. Batten, P. Sarathchandra, J. W. Antoniw, et al. Human mesenchymal stem cells induce $T$ cell anergy and downregulate $T$ cell alloresponses via the TH2 pathway: relevance to tissue engineering human heart valves. Tissue Eng 2006;12:2263-2273.

143 Y. S. Choi, J. A. Jeong, D. S. Lim. Mesenchymal stem cell-mediated immature dendritic cells induce regulatory T cell-based immunosuppressive effect. Immunol Invest 2012;41:214-229.

144 J. Maggini, G. Mirkin, I. Bognanni, et al. Mouse bone marrowderived mesenchymal stromal cells turn activated macrophages into a regulatory-like profile. PLoS ONE 2010;5:e9252.

145 E. Gonzalez-Rey, P. Anderson, M. A. González, et al. Human adult stem cells derived from adipose tissue protect against experimental colitis and sepsis. Gut 2009;58:929-939.

146 M. A. González, E. Gonzalez-Rey, L. Rico, et al. Adipose-derived mesenchymal stem cells alleviate experimental colitis by inhibiting inflammatory and autoimmune responses. Gastroenterology 2009;136:978-989.

147 L. Liang, C. Dong, X. Chen, et al. Human umbilical cord mesenchymal stem cells ameliorate mice trinitrobenzene sulfonic acid (TNBS)-induced colitis. Cell Transplant 2011;20:1395-1408.

148 X. W. He, X. S. He, L. Lian, et al. Systemic infusion of bone marrowderived mesenchymal stem cells for treatment of experimental colitis in mice. Dig Dis Sci 2012;57:3136-3144.

149 B. Parekkadan, R. Upadhyay, J. Dunham, et al. Bone marrow stromal cell transplants prevent experimental enterocolitis and require host $\mathrm{CD} 1 \mathrm{~b}^{+}$splenocytes. Gastroenterology 2011;140: 966-975.

150 Q. Q. Chen, L. Yan, C. Z. Wang, et al. Mesenchymal stem cells alleviate TNBS-induced colitis by modulating inflammatory and autoimmune responses. World J Gastroenterol 2013;19:4702-4717.

151 A. Augello, R. Tasso, S. M. Negrini, et al. Bone marrow mesenchymal progenitor cells inhibit lymphocyte proliferation by activation of the programmed death 1 pathway. Eur J Immunol 2005;35: 1482-1490.

152 W. Deng, Q. Han, L. Liao, et al. Effects of allogeneic bone marrowderived mesenchymal stem cells on $\mathrm{T}$ and $\mathrm{B}$ lymphocytes from BXSB mice. DNA Cell Biol 2005;24:458-463.

153 A. Corcione, F. Benvenuto, E. Ferretti, et al. Human mesenchymal stem cells modulate B-cell functions. Blood 2006;107:367-372.
154 E. Traggiai, S. Volpi, F. Schena, et al. Bone marrow-derived mesenchymal stem cells induce both polyclonal expansion and differentiation of B cells isolated from healthy donors and systemic lupus erythematosus patients. Stem Cells 2008;26:562-569.

155 P. A. Sotiropoulou, S. A. Perez, A. D. Gritzapis, et al. Interactions between human mesenchymal stem cells and natural killer cells. Stem Cells 2006;24:74-85.

156 G. M. Spaggiari, A. Capobianco, H. Abdelrazik, et al. Mesenchymal stem cells inhibit natural killer-cell proliferation, cytotoxicity, and cytokine production: role of indoleamine 2,3-dioxygenase and prostaglandin E2. Blood 2008;111:1327-1333.

157 M. Krampera, L. Cosmi, R. Angeli, et al. Role for interferon- $\gamma$ in the immunomodulatory activity of human bone marrow mesenchymal stem cells. Stem Cells 2006;24:386-398.

158 I. Rasmusson, O. Ringdén, B. Sundberg, K. Le Blanc. Mesenchymal stem cells inhibit the formation of cytotoxic $\mathrm{T}$ lymphocytes, but not activated cytotoxic T lymphocytes or natural killer cells. Transplantation 2003;76:1208-1213.

159 P. A. Sotiropoulou, S. A. Perez, M. Salagianni, et al. Characterization of the optimal culture conditions for clinical scale production of human mesenchymal stem cells. Stem Cells 2006; 24:462-471.

160 A. J. Nauta, A. B. Kruisselbrink, E. Lurvink, et al. Mesenchymal stem cells inhibit generation and function of both $\mathrm{CD} 34^{+}$-derived and monocyte-derived dendritic cells. J Immunol 2006;177: 2080-2087.

161 R. Ramasamy, H. Fazekasova, E. W. Lam, et al. Mesenchymal stem cells inhibit dendritic cell differentiation and function by preventing entry into the cell cycle. Transplantation 2007;83:71-76.

162 K. English, F. P. Barry, B. P. Mahon. Murine mesenchymal stem cells suppress dendritic cell migration, maturation and antigen presentation. Immunol Letters 2008;115:50-58.

163 S. Aggarwal, M. F. Pittenger. Human mesenchymal stem cells modulate allogeneic immune cell responses. Blood 2005;105: 1815-1822.

164 S. Chiesa, S. Morbelli, S. Morando, et al. Mesenchymal stem cells impair in vivo T cell priming by dendritic cells. Proc Natl Acad Sci U S A 2011;108:17384-17389.

165 Y. P. Li, S. Paczesny, E. Lauret, et al. Human mesenchymal stem cells license adult CD $34^{+}$hemopoietic progenitor cells to differentiate into regulatory dendritic cells through activation of the Notch pathway. J Immunol 2008;180:1598-1608.

166 B. Zhang, R. Liu, D. Shi, et al. Mesenchymal stem cells induce mature dendritic cells into a novel Jagged-2-dependent regulatory dendritic cell population. Blood 2009;113:46-57.

167 K. Németh, A. Leelahavanichkul, P. S. Yuen, et al. Bone marrow stromal cells attenuate sepsis via prostaglandin $\mathrm{E}_{2}$-dependent reprogramming of host macrophages to increase their interleukin-10 production. Nat Med 2009;15:42-49.

168 P. Anderson, L. Souza-Moreira, M. Morell, et al. Adipose-derived mesenchymal stromal cells induce immunomodulatory macrophages which protect from experimental colitis and sepsis. Gut 2013;62:1131-1141.

169 G. Ren, J. Su, L. Zhang, et al. Species variation in the mechanisms of mesenchymal stem cell-mediated immunosuppression. Stem Cells 2009;27:1954-1962.

170 M. Matysiak, W. Orlowski, M. Fortak-Michalska, et al. Immunoregulatory function of bone marrow mesenchymal stem cells in 
EAE depends on their differentiation state and secretion of PGE2. J Neuroimmunol 2011;233:106-111.

171 R. Meisel, A. Zibert, M. Laryea, et al. Human bone marrow stromal cells inhibit allogeneic $\mathrm{T}$ cell responses by indoleamine 2,3-dioxygenase-mediated tryptophan degradation. Blood 2004;103:4619-4621.

172 K. Sato, K. Ozaki, I. Oh, et al. Nitric oxide plays a critical role in suppression of $\mathrm{T}$ cell proliferation by mesenchymal stem cells. Blood 2007;109:228-234.

173 G. Ren, L. Zhang, X. Zhao, et al. Mesenchymal stem cell-mediated immunosuppression occurs via concerted action of chemokines and nitric oxide. Cell Stem Cell 2008;2:141-150.

174 A. Nasef, N. Mathieu, A. Chapel, et al. Immunosuppressive effects of mesenchymal stem cells: involvement of HLA-G. Transplantation 2007;84:231-237.

175 L. A. Ortiz, M. Dutreil, C. Fattman, et al. Interleukin 1 receptor antagonist mediates the antiinflammatory and antifibrotic effect of mesenchymal stem cells during lung injury. Proc Natl Acad Sci U S A 2007;104:11002-11007.

176 H. Choi, R. H. Lee, N. Bazhanov, et al. Anti-inflammatory protein TSG- 6 secreted by activated MSCs attenuates zymosan-induced mouse peritonitis by decreasing TLR2/NF- $\kappa \mathrm{B}$ signaling in resident macrophages. Blood 2011;118:330-338.

177 H. S. Kim, T. H. Shin, B. C. Lee, et al. Human umbilical cord blood mesenchymal stem cells reduce colitis in mice by activating NOD2 signaling to COX2. Gastroenterology 2013;145:1392-1403.

178 B. Parekkadan, A. L. Fletcher, M. Li, et al. Aire controls mesenchymal stem cell-mediated suppression in chronic colitis. Mol Ther 2012;20:178-186.

179 O. DelaRosa, E. Lombardo. Modulation of adult mesenchymal stem cells activity by toll-like receptors: implications on therapeutic potential. Mediat Inflamm 2010;2010:865601.

180 R. S. Waterman, S. L. Tomchuck, S. L. Henkle, A. M. Betancourt. A new mesenchymal stem cell (MSC) paradigm: polarization into a pro-inflammatory MSC1 or an immunosuppressive MSC2 phenotype. PLoS ONE 2010;5:e10088.

181 M. Pevsner-Fischer, V. Morad, M. Cohen-Sfady, et al. Toll-like receptors and their ligands control mesenchymal stem cell functions. Blood 2007;109:1422-1432.

182 M. Duijvestein, M. E. Wildenberg, M. M. Welling, et al. Pretreatment with interferon- $\gamma$ enhances the therapeutic activity of mesenchymal stromal cells in animal models of colitis. Stem Cells 2011;29:1549-1558.

183 H. Fan, G. Zhao, L. Liu, et al. Pre-treatment with IL-1 $\beta$ enhances the efficacy of MSC transplantation in DSS-induced colitis. Cell Mol Immunol 2012;9:473-481.

184 K. Le Blanc, C. Tammik, K. Rosendahl, et al. HLA expression and immunologic properties of differentiated and undifferentiated mesenchymal stem cells. Exp Hematol 2003;31:890-896.

185 W. T. Tse, J. D. Pendleton, W. M. Beyer, et al. Suppression of allogeneic $\mathrm{T}$ cell proliferation by human marrow stromal cells: implications in transplantation. Transplantation 2003;75:389-397.

186 G. M. Spaggiari, A. Capobianco, S. Becchetti, et al. Mesenchymal stem cell-natural killer cell interactions: evidence that activated NK cells are capable of killing MSCs, whereas MSCs can inhibit IL-2induced NK-cell proliferation. Blood 2006;107:1484-1490.

187 M. Francois, R. Romieu-Mourez, S. Stock-Martineau, et al. Mesenchymal stromal cells cross-present soluble exogenous antigens as part of their antigen-presenting cell properties. Blood 2009;114:2632-2638.

188 R. Romieu-Mourez, M. Francois, M. N. Boivin, et al. Regulation of MHC class II expression and antigen processing in murine and human mesenchymal stromal cells by IFN- $\gamma$, TGF- $\beta$, and cell density. J Immunol 2007;179:1549-1558.

189 W. K. Chan, A. S. Lau, J. C. Li, et al. MHC expression kinetics and immunogenicity of mesenchymal stromal cells after short-term IFN- $\gamma$ challenge. Exp Hematol 2008;36:1545-1555.

190 J. Stagg, S. Pommey, N. Eliopoulos, et al. Interferon- $\gamma$-stimulated marrow stromal cells: a new type of nonhematopoietic antigenpresenting cell. Blood 2006;107:2570-2577.

191 A. J. Nauta, G. Westerhuis, A. B. Kruisselbrink, et al. Donor-derived mesenchymal stem cells are immunogenic in an allogeneic host and stimulate donor graft rejection in a nonmyeloablative setting. Blood 2006;108:2114-2120.

192 P. Sbano, A. Cuccia, B. Mazzanti, et al. Use of donor bone marrow mesenchymal stem cells for treatment of skin allograft rejection in a preclinical rat model. Arch Dermatol Res 2008;300:115-124.

193 S. Schu, M. Nosov, L. O’Flynn, et al. Immunogenicity of allogeneic mesenchymal stem cells. J Cell Mol Med 2012;16:2094-2103.

194 X-P. Huang, Z. Sun, Y. Miyagi, et al. Differentiation of allogeneic mesenchymal stem cells induces immunogenicity and limits their long-term benefits for myocardial repair. Circulation 2010;122: 2419-2429.

195 S. M. Devine, C. Cobbs, M. Jennings, et al. Mesenchymal stem cells distribute to a wide range of tissues following systemic infusion into nonhuman primates. Blood 2003;101:2999-3001.

196 F. Tanaka, K. Tominaga, M. Ochi, et al. Exogenous administration of mesenchymal stem cells ameliorates dextran sulfate sodiuminduced colitis via anti-inflammatory action in damaged tissue in rats. Life Sci 2008;83:771-779.

197 M. T. Castelo-Branco, I. D. Soares, D. V. Lopes, et al. Intraperitoneal but not intravenous cryopreserved mesenchymal stromal cells home to the inflamed colon and ameliorate experimental colitis. PLoS ONE 2012;7:e33360.

198 E. Spaeth, A. Klopp, J. Dembinski, et al. Inflammation and tumor microenvironments: defining the migratory itinerary of mesenchymal stem cells. Gene Ther 2008;15:730-738.

199 H. Yagi, A. Soto-Gutierrez, B. Parekkadan, et al. Mesenchymal stem cells: Mechanisms of immunomodulation and homing. Cell Transplant 2010;19:667-679.

200 I. K. Ko, B. G. Kim, A. Awadallah, et al. Targeting improves MSC treatment of inflammatory bowel disease. Mol Ther 2010;18: 1365-1372.

201 S. Wakitani, T. Saito, A. I. Caplan. Myogenic cells derived from rat bone marrow mesenchymal stem cells exposed to 5-azacytidine. Muscle Nerve 1995;18:1417-1426.

202 R. A. Rose, A. Keating, P. H. Backx. Do mesenchymal stromal cells transdifferentiate into functional cardiomyocytes? Circ Res 2008; 103:e120.

203 O. K. Lee, T. K. Kuo, W. M. Chen, et al. Isolation of multipotent mesenchymal stem cells from umbilical cord blood. Blood 2004;103:1669-1675.

204 D. Woodbury, E. J. Schwarz, D. J. Prockop, I. B. Black. Adult rat and human bone marrow stromal cells differentiate into neurons. J Neurosci Res 2000;61:364-370. 
205 P. Tropel, N. Platet, J. C. Platel, et al. Functional neuronal differentiation of bone marrow-derived mesenchymal stem cells. Stem Cells 2006;24:2868-2876.

206 K. Singaravelu, B. J. Padanilam. In vitro differentiation of MSC into cells with a renal tubular epithelial-like phenotype. Ren Fail 2009;31:492-502.

207 R. E. Schwartz, M. Reyes, L. Koodie, et al. Multipotent adult progenitor cells from bone marrow differentiate into functional hepatocyte-like cells. J Clin Invest 2002;109:1291-1302.

208 R. Taléns-Visconti, A. Bonora, R. Jover, et al. Human mesenchymal stem cells from adipose tissue: differentiation into hepatic lineage. Toxicol In Vitro 2007;21:324-329.

209 M. J. Seo, S. Y. Suh, Y. C. Bae, J. S. Jung Differentiation of human adipose stromal cells into hepatic lineage in vitro and in vivo. Biochem Biophys Res Commun 2005;328:258-264.

210 V. Sordi. Mesenchymal stem cell homing capacity. Transplantation 2009;87:S42-S45.

211 T. J. Cashman, V. Gouon-Evans, K. D. Costa. Mesenchymal stem cells for cardiac therapy: practical challenges and potential mechanisms. Stem Cell Rev 2013;9:254-265.

212 U. Kunter, S. Rong, Z. Djuric, et al. Transplanted mesenchymal stem cells accelerate glomerular healing in experimental glomerulonephritis. J Am Soc Nephrol 2006;17:2202-2212.

213 M. B. Herrera, B. Bussolati, S. Bruno, et al. Mesenchymal stem cells contribute to the renal repair of acute tubular epithelial injury. Int $J$ Mol Med 2004;14:1035-1041.

214 R. P. Meier, Y. D. Müller, P. Morel, et al. Transplantation of mesenchymal stem cells for the treatment of liver diseases, is there enough evidence? Stem Cell Res 2013;11:1348-1364.

215 A. C. Inamdar, A. A. Inamdar. Mesenchymal stem cell therapy in lung disorders: pathogenesis of lung diseases and mechanism of action of mesenchymal stem cell. Exp Lung Res 2013;39:315-327.

216 F. Xu, Y. Hu, J. Zhou, X. Wang. Mesenchymal stem cells in acute lung injury: are they ready for translational medicine? J Cell Mol Med 2013;17:927-935.

217 G. Paul, S. V. Anisimov. The secretome of mesenchymal stem cells: potential implications for neuroregeneration. Biochimie 2013;95:2246-2256.

218 Y. Hayashi, S. Tsuji, M. Tsujii, et al. Topical implantation of mesenchymal stem cells has beneficial effects on healing of experimental colitis in rats. J Pharmacol Exp Ther 2008;326:523-531.

219 T. Yabana, Y. Arimura, H. Tanaka, et al. Enhancing epithelial engraftment of rat mesenchymal stem cells restores epithelial barrier integrity. J Pathol 2009;218:350-359.

220 D. J. Prockop. "Stemness" does not explain the repair of many tissues by mesenchymal stem/multipotent stromal cells (MSCs). Clin Pharmacol Ther 2007;82:241-243.

221 S. Kachgal, A. J. Putnam. Mesenchymal stem cells from adipose and bone marrow promote angiogenesis via distinct cytokine and protease expression mechanisms. Angiogenesis 2011;14:47-59.

222 A. I. Caplan. Why are MSCs therapeutic? New data: new insight. J Pathol 2009;217:318-324.

223 D. García-Olmo, M. García-Arranz, D. Herreros, et al. A phase I clinical trial of the treatment of Crohn's fistula by adipose mesenchymal stem cell transplantation. Dis Colon Rectum 2005;48 1416-1423.

224 D. García-Olmo, M. García-Arranz, D. Herreros. Expanded adipose-derived stem cells for the treatment of complex perianal fistula including Crohn's disease. Expert Opin Biol Ther 2008;8: $1417-1423$

225 D. García-Olmo, D. Herreros, I. Pascual, et al. Expanded adiposederived stem cells for the treatment of complex perianal fistula: a phase II clinical trial. Dis Colon Rectum 2009;52:79-86.

226 H. Guadalajara, D. Herreros, P. De-La-Quintana, et al. Long-term follow-up of patients undergoing adipose-derived adult stem cell administration to treat complex perianal fistulas. Int J Colorectal Dis 2012;27:595-600.

227 Y. B. Cho, W. Y. Lee, K. J. Park, et al. Autologous adipose tissuederived stem cells for the treatment of Crohn's fistula: a phase I clinical study. Cell Transplant 2013;22:279-285.

228 W. Y. Lee, K. J. Park, Y. B. Cho, et al. Autologous adipose tissuederived stem cells treatment demonstrated favorable and sustainable therapeutic effect for Crohn's fistula. Stem Cells 2013;31: 2575-2581.

229 R. Ciccocioppo, M. E. Bernardo, A. Sgarella, et al. Autologous bone marrow-derived mesenchymal stromal cells in the treatment of fistulising Crohn's disease. Gut 2011;60:788-798.

230 F. de la Portilla, F. Alba, D. García-Olmo, et al. Expanded allogeneic adipose-derived stem cells (eASCs) for the treatment of complex perianal fistula in Crohn's disease: results from a multicenter phase I/IIa clinical trial. Int J Colorectal Dis 2013;28:313-323.

231 M. Duijvestein, A. C. Vos, H. Roelofs, et al. Autologous bone marrow-derived mesenchymal stromal cell treatment for refractory luminal Crohn's disease: results of a phase I study. Gut 2010;59:1662-1669.

232 J. Onken, D. Gallup, J. Hanson, et al. Successful outpatient treatment of refractory Crohn's disease using adult mesenchymal stem cells. In: Proceedings of the American College of Gastroenterology Conference 2006, Las Vegas, NV, Abstract 121.

233 J. Liang, H. Zhang, D. Wang, et al. Allogeneic mesenchymal stem cell transplantation in seven patients with refractory inflammatory bowel disease. Gut 2012;61:468-469.

234 Bonab MM, Alimoghaddam K, Talebian F, et al. Aging of mesenchymal stem cell in vitro. BMC Cell Biol 2006;7:14.

235 D. García-Olmo, D. Herreros, M. Pascual, et al. Treatment of enterocutaneous fistula in Crohn's disease with adipose-derived stem cells: a comparison of protocols with and without cell expansion. Int J Colorectal Dis 2009;24:27-30.

236 I. Bochev, G. Elmadjian, D. Kyurkchiev, et al. Mesenchymal stem cells from human bone marrow or adipose tissue differently modulate mitogen-stimulated B-cell immunoglobulin production in vitro. Cell Biol Int 2008;32:384-393.

237 E. Ivanova-Todorova, I. Bochev, M. Mourdjeva, et al. Adipose tissue-derived mesenchymal stem cells are more potent suppressors of dendritic cells differentiation compared to bone marrow-derived mesenchymal stem cells. Immunol Lett 2009;126:37-42.

238 L. Y. Sun, H. Y. Zhang, X. B. Feng, et al. Abnormality of bone marrow-derived mesenchymal stem cells in patients with systemic lupus erythematosus. Lupus 2007;16:121-128.

239 C. Bocelli-Tyndall, L. Bracci, G. Spagnoli, et al. Bone marrow mesenchymal stromal cells (BM-MSCs) from healthy donors and auto-immune disease patients reduce the proliferation of autologous- and allogeneic-stimulated lymphocytes in vitro. Rheumatology (Oxford) 2007;46:403-408.

240 L. Dinesen, A. Wang, F. Vianello, et al. Mesenchymal stem cells administered via novel selective mesenteric artery cannulation for 
the treatment of severe refractory Crohn's disease. J Crohns Colitis 2010;3:S51-S52.

241 M. Duijvestein, I. Molendijk, H. Roelofs, et al. Mesenchymal stromal cell function is not affected by drugs used in the treatment of inflammatory bowel disease. Cytotherapy 2011;13:1066-1073.

242 F. Baron, R. Storb. Mesenchymal stromal cells: a new tool against graft-versus-host disease? Biol Blood Marrow Transplant 2012;18: 822-840.

243 K. Le Blanc, F. Frassoni, L. Ball, et al. Mesenchymal stem cells for treatment of steroid-resistant, severe, acute graft-versus-host disease: a phase II study. Lancet 2008;371:1579-1586.

244 F. Baron, C. Lechanteur, E. Willems, et al. Cotransplantation of mesenchymal stem cells might prevent death from graft-versushost disease (GVHD) without abrogating graft-versus-tumor effects after HLA-mismatched allogeneic transplantation following nonmyeloablative conditioning. Biol Blood Marrow Transplant 2010;16:838-847.

$245 \mathrm{~J}$ Tan, W. Wu, X. Xu, et al. Induction therapy with autologous mesenchymal stem cells in living-related kidney transplants: a randomized controlled trial. JAMA 2012;307:1169-1177.

246 S. Wakitani, T. Okabe, S. Horibe, et al. Safety of autologous bone marrow-derived mesenchymal stem cell transplantation for cartilage repair in 41 patients with 45 joints followed for up to 11 years and 5 months. J Tissue Eng Regen Med 2011;5:146-150.

247 W. R. Otto, N. A. Wright. Mesenchymal stem cells: from experiment to clinic. Fibrogenesis Tissue Repair 2011;4:20.

248 M. M. Lalu, L. McIntyre, C. Pugliese, et al. Safety of cell therapy with mesenchymal stromal cells (SafeCell): a systematic review and meta-analysis of clinical trials. PLoS ONE 2012;7:e47559.

249 Y. F. Zhou, M. Bosch-Marce, H. Okuyama, et al. Spontaneous transformation of cultured mouse bone marrow-derived stromal cells. Cancer Res 2006;66:10849-10854.

250 M. Miura, Y. Miura, H. M. Padilla-Nash, et al. Accumulated chromosomal instability in murine bone marrow mesenchymal stem cells leads to malignant transformation. Stem Cells 2006;24:1095-1103.

251 F. Casiraghi, G. Remuzzi, M. Abbate, N. Perico. Multipotent mesenchymal stromal cell therapy and risk of malignancies. Stem Cell Rev 2013;9:65-79.
252 M. E. Bernardo, N. Zaffaroni, F. Novara, et al. Human bone marrow derived mesenchymal stem cells do not undergo transformation after long-term in vitro culture and do not exhibit telomere maintenance mechanisms. Cancer Res 2007;67: 9142-9149.

253 D.J. Prockop, M. Brenner, W. E. Fibbe, et al. Defining the risks of mesenchymal stromal cell therapy. Cytotherapy 2010;12:576-578.

254 Z. Chen, X. He, X. He, et al. Bone marrow mesenchymal stem cells ameliorate colitis-associated tumorigenesis in mice. Biochem Biophys Res Commun 2014;450:1402-1408.

255 G. Ren, X. Zhao, Y. Wang, et al. CCR2-dependent recruitment of macrophages by tumor-educated mesenchymal stromal cells promotes tumor development and is mimicked by TNF $\alpha$. Cell Stem Cell 2012;11:812-824.

256 B. Song, B. Kim, S. H. Choi, et al. Mesenchymal stromal cells promote tumor progression in fibrosarcoma and gastric cancer cells. Korean J Pathol 2014;48:217-224.

257 H. Lee Ryang, N. Yoon, J. C. Reneau, D. J. Prockop. Preactivation of human MSCs with TNF-a enhances tumor-suppressive activity. Cell Stem Cell 2012;11:825-835.

258 S. H. Abd-Allah, S. M. Shalaby, A. S. El-Shal, et al. Effect of bone marrow-derived mesenchymal stromal cells on hepatoma. Cytotherapy 2014;16:1197-1206.

259 C. Yang, D. Lei, W. Ouyang, et al. Conditioned media from human adipose tissue-derived mesenchymal stem cells and umbilical cordderived mesenchymal stem cells efficiently induced the apoptosis and differentiation in human glioma cell lines in vitro. Biomed Res Int 2014;2014:109389.

260 A. Mantovani. MSCs, macrophages, and cancer: a dangerous ménage-à-trois. Cell Stem Cell 2012;11:730-732.

261 G. Lazennec, C. Jorgensen. Concise review: adult multipotent stromal cells and cancer: risk or benefit? Stem Cells 2008;26: 1387-1394.

262 H. Ning, F. Yang, M. Jiang, et al. The correlation between cotransplantation of mesenchymal stem cells and higher recurrence rate in hematologic malignancy patients: outcome of a pilot clinical study. Leukemia 2008;22:593-539. 